The INL is a

U.S. Department of Energy

National Laboratory

operated by

Battelle Energy Alliance

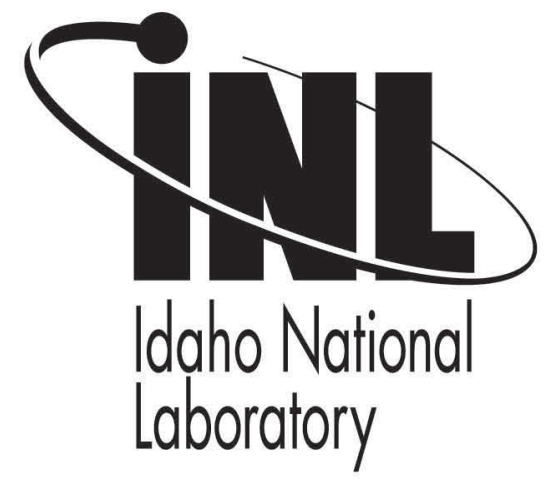

INL/CON-10-17934

PREPRINT

\section{Development of a Computational}

Multiphase Flow Model

for Fischer Tropsch

Synthesis in a Slurry

Bubble Column Reactor

XIX International Conference on

Chemical Reactors (CHEMREACTOR-

19)

Donna Post Guillen

Tami Grimmett

Anastasia M. Gandrik

Steven P. Antal

\section{September 2010}

This is a preprint of a paper intended for publication in a journal or proceedings. Since changes may be made before publication, this preprint should not be cited or reproduced without permission of the author. This document was prepared as an account of work sponsored by an agency of the United States Government. Neither the United States Government nor any agency thereof, or any of their employees, makes any warranty, expressed or implied, or assumes any legal liability or responsibility for any third party's use, or the results of such use, of any information, apparatus, product or process disclosed in this report, or represents that its use by such third party would not infringe privately owned rights. The views expressed in this paper are not necessarily those of the United States Government or the sponsoring agency. 


\title{
DEVELOPMENT OF A COMPUTATIONAL MULTIPHASE FLOW MODEL FOR FISCHER TROPSCH SYNTHESIS IN A SLURRY BUBBLE COLUMN REACTOR
}

\author{
Donna Post Guillen ${ }^{1}$, Tami Grimmett ${ }^{1}$, Anastasia M. Gandrik ${ }^{1}$ and Steven P. Antal ${ }^{2}$ \\ ${ }^{1}$ Idaho National Laboratory Idaho Falls, Idaho, 83415 USA, Donna.Guillen@inl.gov \\ ${ }^{2}$ Interphase Dynamics, Ballston Lake, NY 12019 USA, antals@rpi.edu
}

\begin{abstract}
The Hybrid Energy Systems Testing (HYTEST) Laboratory at the Idaho National Laboratory was established to develop and test hybrid energy systems with the principal objective of reducing dependence on imported fossil fuels. A central component of the HYTEST is the slurry bubble column reactor (SBCR) in which the gas-to-liquid reactions are performed to synthesize transportation fuels using the Fischer Tropsch (FT) process. These SBCRs operate in the churn-turbulent flow regime, which is characterized by complex hydrodynamics, coupled with reacting flow chemistry and heat transfer. Results Our team is developing a research tool to aid in understanding the physicochemical processes occurring in the SBCR. A robust methodology to couple reaction kinetics and mass transfer into a four-field model (consisting of the bulk liquid, small bubbles, large bubbles and solid catalyst particles) consisting of thirteen species, which are $\mathrm{CO}$ reactant, $\mathrm{H}_{2}$ reactant, hydrocarbon product, and $\mathrm{H}_{2} \mathrm{O}$ product in small bubbles, large bubbles, and the bulk fluid plus catalyst is outlined. Mechanistic submodels for interfacial momentum transfer in the churn-turbulent flow regime are incorporated, along with bubble breakup/coalescence and two-phase turbulence submodels. The absorption and kinetic models, specifically changes in species concentrations, have been incorporated into the mass continuity equation. The reaction rate is based on the macrokinetic model for a cobalt catalyst developed by Yates and Satterfield. The model includes heat generation produced by the exothermic chemical reaction, as well as heat removal from a constant temperature heat exchanger. A property method approach is employed to incorporate vapor-liquid equilibrium (VLE) in a robust manner. Physical and thermodynamic properties as functions of changes in both pressure and temperature are obtained from VLE calculations performed external to the CMFD solver. The novelty of this approach is in its simplicity, as well as its accuracy over a specified temperature and pressure range.
\end{abstract}

Keywords: churn-turbulent flow; Fischer Tropsch; slurry bubble column reactor; computational multiphase fluid dynamics

\section{Introduction}

The Hybrid Energy Systems Testing (HYTEST) Laboratory is being established at the Idaho National Laboratory to develop and test hybrid energy systems with the principal objective to safeguard U.S. Energy Security by reducing dependence on foreign petroleum. A central component of the HYTEST is the slurry bubble column reactor (SBCR) in which the gas-to-liquid reactions will be performed to synthesize transportation fuels using the Fischer Tropsch (FT) process. SBCRs are cylindrical vessels in which gaseous reactants (for example, synthesis gas or syngas) is sparged into a slurry of liquid reaction products and finely dispersed catalyst particles. The catalyst particles are transported in the slurry by the rising gas bubbles and serve to promote the chemical reaction that converts syngas to a spectrum of longer chain hydrocarbon products, which can be upgraded to gasoline, diesel or jet fuel.

These SBCRs operate in the churn-turbulent flow regime [1] which is characterized by complex hydrodynamics, coupled with reacting flow chemistry and heat transfer, that affect reactor performance. 
The purpose of this work is to develop a research tool to aid in understanding the physicochemical processes occurring in the SBCR. Our team is developing a robust methodology to couple reaction kinetics and mass transfer into a four-field model (consisting of the bulk liquid, small bubbles, large bubbles and solid catalyst particles) consisting of thirteen species, which are $\mathrm{CO}$ reactant, $\mathrm{H}_{2}$ reactant, hydrocarbon product, and $\mathrm{H}_{2} \mathrm{O}$ product in small bubbles, large bubbles, and the bulk fluid plus catalyst. This paper describes the computational multiphase fluid dynamics platform on which the model is constructed. The Eulerian-Eulerian multifield formulation is provided, along with the mechanistic submodels for interfacial momentum transfer in the churn-turbulent flow regime, and the bubble breakup/coalescence and two-phase turbulence submodels. The absorption and kinetic models, specifically changes in species concentrations, have been incorporated into the mass continuity equation. The reaction rate is determined based on the macrokinetic model for a cobalt catalyst developed by Yates and Satterfield [2]. The model includes heat generation produced by the exothermic chemical reaction, as well as heat removal from a constant temperature heat exchanger. A property method approach is employed to incorporate vapor-liquid equilibrium (VLE) in a robust manner. Physical and thermodynamic properties as functions of changes in both pressure and temperature are obtained from VLE calculations performed external to the CMFD solver. The novelty of this approach is in its simplicity, as well as its accuracy over a specified temperature and pressure range. The focus on this paper is on the property method approach for incorporating VLE into the FT SBCR model.

Thorough testing and validation is essential for any computational model, especially for the submodels coupled to the CMFD code. To assess the fidelty of model predictions, the hydrodynamics predicted by the CFD code have been compared with experimental data for adiabatic two-phase flow in the churn-turbulent regime. A hierarchy for testing and validation of the complete model is outlined.

\section{Computational Multiphase Fluid Dynamics (CMFD) Platform}

The computational platform for this work is the NPHASE-CMFD computer program, an unstructured, finite-volume, multifield, pressure-based computational multiphase fluid dynamics (CMFD) computer code offering both segregated and fully coupled multifield numerical solution methods. To achieve numerical convergence for multiphase flows, simulations are performed using the robust, coupled algorithm, which fully couples the phasic mass and momentum equations to solve for the phasic velocity, pressure, and volume fraction simultaneously. Although, the computer memory requirements are increased, this ability to couple the conservation of mass and momentum equations is more robust than the use of a segregated solver. A full three-dimensional, Eulerian-Eulerian framework is employed, rather than tracking a very large number of individual bubble trajectories. Ensemble-averaged conservation equations for mass and momentum are solved for an arbitrary number of fields. The equations are discretized into a block matrix system, which is solved by an algebraic multigrid solver. A detailed derivation of the ensemble-averaged conservation equations has been given by Drew and Passman [3]. The fully coupled mass/momentum scheme allows any field to interact with any other field within the multigrid matrix system. Interfacial mass, momentum and turbulence submodels provide coupling between the fields. The following subsections describe the multifield model formulation and the submodels implemented in NPHASE-CMFD for bubble breakup and coalescence, two-phase turbulence and interfacial momentum exchange. 


\subsection{Multifield Model Formulation}

In this Eulerian-Eulerian (EE) formulation, the different phases are treated as interpenetrating continua. Within this framework, even the dispersed phase (the gas bubbles) is treated as a continuum. The probability of each phase at any location is indicated by the volume fraction. An EE approach is suitable even if the volume fraction of the dispersed phase is large [4]. The laws of conservation of mass and momentum are satisfied for both large and small bubbles and the local phasic velocity and volume fraction are calculated at each node. The phasic conservation of mass equation is expressed as

$$
\frac{\partial}{\partial t}\left(\varepsilon_{k} \rho_{k}\right)+\nabla \cdot\left(\varepsilon_{k} \rho_{k} v_{k}\right)=\Gamma_{k}^{\prime \prime \prime}+m_{k}^{\prime \prime \prime}
$$

where $\Gamma_{k}^{\prime \prime \prime}$ is the volumetric mass transfer rate due to phase change; $m_{k}^{\prime \prime \prime}$ is the volumetric mass transfer into field-k from other fields having the same phase; $\varepsilon_{\mathrm{k}}$ is the volume fraction; $\rho_{\mathrm{k}}\left(\mathrm{kg} / \mathrm{m}^{3}\right)$ is the phasic density; and $v_{k}(\mathrm{~m} / \mathrm{s})$ is the velocity. The number of fields of each phase is user-defined and allows different flow physics to be included for each field.

The ensemble-averaged, phasic momentum conservation equation can be reduced to the following approximate multifield formulation [5]

$$
\frac{\partial}{\partial \mathrm{t}}\left(\varepsilon_{\mathrm{k}} \rho_{\mathrm{k}} \mathrm{v}_{\mathrm{k}}\right)+\nabla \cdot\left(\varepsilon_{\mathrm{k}} \rho_{\mathrm{k}} \mathrm{v}_{\mathrm{k}} \mathrm{v}_{\mathrm{k}}\right)=-\varepsilon_{\mathrm{k}} \nabla \mathrm{p}+\nabla \cdot \varepsilon_{\mathrm{k}} \underset{\mathrm{\tau}}{\mathrm{\tau}}+\varepsilon_{\mathrm{k}} \rho_{\mathrm{k}} \mathrm{g}+\sum_{\mathrm{j}} \mathrm{M}_{\mathrm{jk}}^{\mathrm{i}}+\Gamma_{\mathrm{k}}^{\prime \prime \prime} \mathrm{v}_{\mathrm{k}}^{\mathrm{i}}+\mathrm{m}_{\mathrm{k}}^{\prime \prime \prime} \mathrm{v}_{\mathrm{k}}
$$

The terms on the right hand side of Equation 2 represent the pressure gradient, shear stress tensor, body force due to gravity, momentum exchange at interfaces and momentum flux due to mass transfer. The superscript $i$ refers to interfacial variables. The compatibility relation included in the coupled solver equation set is expressed as the summation of the volume fractions of the various fields

$$
\sum_{\mathrm{k}} \varepsilon_{\mathrm{k}}=1
$$

which must sum to unity.

The literature indicates that churn-turbulent flow should be modeled as a continuous liquid phase with at least two dispersed bubble size groups [6]. In a four-field model, field 1 represents the continuous liquid phase, fields 2 and 3 represent the two dispersed bubble size groups, and field 4 is the catalyst. Each bubble group is treated as a separate field to allow appropriate interfacial flow physics for the different bubble size groups to be included via the closure models. The use of mechanistic closure models for bubble forces is discussed in detail in a subsequent subsection.

For churn-turbulent flows an understanding of the expected bubble distribution is needed. Flow structure visualization studies [7] show a clear separation of bubble sizes. In reality, the bubble size distribution is polydisperse as evidenced by the experimental data [8], but since the bubble size distribution is largely bimodal, such flows are often successfully simplified by considering the flow to consist of a small and a large bubble group. Two bubble groups are the minimum number of size groups needed since the interfacial forces act quite different between the groups. The criterion used for classifying bubble size as either small or large is based bubble chord length given by [9] as

$$
\mathrm{D}_{\mathrm{cr}}=4 \sqrt{\frac{\sigma}{\mathrm{g}\left(\rho_{\mathrm{c}}-\rho_{\mathrm{d}}\right)}}
$$

where $g\left(\mathrm{~m}^{2} / \mathrm{s}\right)$ is gravitational acceleration and $\sigma$ is the surface tension $(\mathrm{N} / \mathrm{m})$ of the bulk liquid. The subscripts $\mathrm{c}$ and denote the continuous phase and dispersed phase, respectively. Bubbles with a size 
smaller than this critical diameter tend to be spherical or ellipsoidal in shape, whereas those larger than this size exhibit a distorted, spherical cap shape.

The phasic energy equation implemented in NPHASE-CMFD is written as

$$
\frac{\partial}{\partial t}\left(\varepsilon_{k} \rho_{k} h_{k}\right)+\nabla \cdot\left(\varepsilon_{k} \rho_{k} v_{k} h_{k}\right)=\nabla \cdot\left[\varepsilon_{k}\left(q^{\prime \prime}+q^{\prime \prime T}\right)\right]+\varepsilon_{k} \Delta H_{k}+U A\left(T_{\text {liq }}-T_{w}\right)+\Gamma_{k}^{\prime \prime \prime} e_{k}^{i}+m_{k}^{\prime \prime \prime} e_{k}
$$

where $h_{k}(J / k g)$ is ensemble-averaged enthalpy; $e_{k}(W)$ is the internal energy for field-k; $q "\left(W / \mathrm{m}^{2}\right)$ is the interfacial heat flux; $\Delta \mathrm{H}\left(\mathrm{W} / \mathrm{m}^{3}\right)$ is the chemical heat of reaction, $\mathrm{U}\left(\mathrm{W} / \mathrm{m}^{2}-\mathrm{K}\right)$ is the overall heat transfer coefficient and $\mathrm{A}\left(\mathrm{m}^{2}\right)$ is the area of the heat exchanger; and $\mathrm{T}_{\mathrm{c}}$ and $\mathrm{T}_{\mathrm{w}}$ are the temperatures $(\mathrm{K})$ of the continuous liquid phase and the heat exchanger wall, respectively. The superscript $T$ indicates the transpose of the tensor. The terms on the right hand side of the equation represent the conductive heat flux, the volumetric heat source due to the chemical reaction, and convective heat transfer to the heat exchanger, respectively. The energy equation is used to predict the change in liquid temperature due to the exothermic chemical reaction and heat exchanger. A simple heat exchanger model has been used which allows heat transfer from the liquid and represented as a constant temperature heat exchanger over the central region of the column. The heat exchanger serves to remove all of the heat of reaction $(\Delta \mathrm{H}=-$ $\left.0.172 \mathrm{MJ} / \mathrm{mol}_{\mathrm{CO}}\right)[1]$.

The local mass fractions of the chemical species are evaluated using species transport equations

$$
\frac{\partial}{\partial t}\left(\varepsilon_{k} \rho_{k} Y_{s}\right)+\nabla \cdot\left(\varepsilon_{k} \rho_{k} v_{k} Y_{s}\right)=\nabla \cdot \varepsilon_{k}\left(\frac{\mu_{k}}{P r_{s}}+\frac{\mu_{k}^{t}}{\operatorname{Pr}_{s}^{t}}\right) \nabla Y_{s}+\Gamma_{k}^{\prime \prime \prime} Y_{k}+m_{k}^{\prime \prime \prime} Y_{k}+S_{s}
$$

where $Y_{s}$ is the species mass fraction, $\mu_{\mathrm{k}}$ and $\mu_{\mathrm{k}}^{\mathrm{t}}$ are the molecular and turbulent viscosity for field-k, $\operatorname{Pr}_{\mathrm{s}}$ and $\operatorname{Pr}_{\mathrm{s}}^{\mathrm{t}}$ are the laminar and turbulent species Prandtl numbers, and $\mathrm{S}_{\mathrm{s}}\left(\mathrm{kg} / \mathrm{m}^{3}-\mathrm{s}\right)$ is the source term containing the reaction kinetics. The species source term due to chemical reactions is summed from the contributions of the reaction rates

$$
\mathrm{S}_{\mathrm{s}}=M \mathrm{WW}_{\mathrm{s}} \sum_{\mathrm{n}=1}^{\mathrm{N}_{\mathrm{R}}} \mathrm{n}_{\mathrm{sn}} \mathrm{R}_{\mathrm{n}}
$$

where $\mathrm{MW}_{\mathrm{s}}$ is the molecular weight $(\mathrm{kg} / \mathrm{mol})$ for species $s, \mathrm{n}_{\mathrm{sn}}$ is the overall stoichiometric coefficient for species $s$ in reaction $n$ (positive for products and negative for reactants), $\mathrm{N}_{\mathrm{R}}$ is the number of reactions and $\mathrm{R}_{\mathrm{n}}$ is the reaction rate for the $\mathrm{n}^{\text {th }}$ reaction. It is assumed that the species are well mixed at the molecular level, that is, they have the same velocity, pressure and temperature as the carrier field.

\subsection{Bubble Breakup and Coalescence Submodel}

Bubble breakup and coalescence are important phenomena occurring in churn-turbulent flows. Small bubbles enter the flow channel and begin coalescing to form new bubbles that are twice the size of the inflow bubbles. As the bubbles rise, the large bubbles can coalesce with either small bubbles or other large bubbles. This coalescence transitions the flow to the churn-turbulent regime. A simple, mechanistically-based breakup and coalescence model is employed wherein the three cases shown in Table 1 are considered. This submodel is described in [10]. 
Table 1. Bubble Interaction Mechanisms.

\begin{tabular}{ccc}
\hline Case & $\begin{array}{c}\text { Mass } \\
\text { Exchange }\end{array}$ & Mechanism \\
\hline 1 & $\mathrm{~m}_{\mathrm{sb}+\mathrm{sb} \rightarrow \mathrm{lb}}^{\prime \prime \prime}$ & small bubbles coalesce with other small bubbles to produce a large bubble \\
\hline 2 & $\mathrm{~m}_{\mathrm{sb}+\mathrm{lb} \rightarrow \mathrm{bb}}^{\prime \prime \prime}$ & small bubbles coalesce with large bubbles to produce a large bubble \\
\hline 3 & $\mathrm{~m}_{\mathrm{lb} \rightarrow \mathrm{sb}}^{\prime \prime \prime}$ & small bubbles stripped from large bubbles to produce small bubbles \\
\hline
\end{tabular}

The overall mass exchange with the small bubble group is given as

$$
\mathrm{m}_{\mathrm{sb}}^{\prime \prime \prime}=\mathrm{m}_{\mathrm{lb} \rightarrow \mathrm{sb}}^{\prime \prime \prime}-\mathrm{m}_{\mathrm{sb}+\mathrm{sb} \rightarrow \mathrm{lb}}^{\prime \prime \prime}-\mathrm{m}_{\mathrm{sb}+\mathrm{lb} \rightarrow \mathrm{lb}}^{\prime \prime \prime}
$$

where the subscript sb indicates "small bubbles" and the subscript lb indicates "large bubbles". For case 1 , the mass transfer rate per unit volume is expressed as

$$
\mathrm{m}_{\mathrm{sb}+\mathrm{sb} \rightarrow \mathrm{lb}}^{\prime \prime \prime}=\mathrm{K}_{\mathrm{sb}+\mathrm{sb} \rightarrow \mid \mathrm{b}} \varepsilon_{\mathrm{sb}}^{2}
$$

where $\mathrm{K}$ is the probability of coalescence between two bubbles given as

$$
\mathrm{K}_{\mathrm{sb}+\mathrm{sb} \rightarrow \mathrm{lb}}=\rho_{\mathrm{d}} \mathrm{P}_{\mathrm{sb}+\mathrm{sb} \rightarrow \mathrm{lb}} \omega_{\mathrm{sb}+\mathrm{sb} \rightarrow \mathrm{lb}}
$$

and $\omega$ is the frequency of collisions and $\mathrm{P}$ is the relative probability of coalescence. The frequency is expressed as

$$
\omega_{\mathrm{sb}+\mathrm{sb} \rightarrow \mathrm{lb}}=\frac{2}{\left(\frac{\mathrm{D}_{\mathrm{lb}}}{\mathrm{D}_{\mathrm{sb}}}\right)^{3}-1}\left[\frac{\mathrm{C}_{\mathrm{BI}}\left|\mathrm{v}_{\mathrm{sb}}-\mathrm{v}_{\mathrm{l}}\right|}{\pi \mathrm{D}_{\mathrm{sb}}}+\frac{\left|\nabla \mathrm{v}_{\mathrm{sb}}\right|}{\left(\mathrm{z}_{\mathrm{cr}}-\varepsilon_{\mathrm{sb}}\right)^{\frac{1}{3}}}\right]
$$

$\mathrm{C}_{\mathrm{BI}}$ is the coefficient of bubble-induced turbulence and $\mathrm{z}_{\mathrm{cr}}$ is the critical packing limit of the small bubbles (0.74 for spherical bubbles [11]).

In a similar manner, the mass transfer rate for case 2 is given by

$$
\begin{gathered}
\mathrm{m}_{\mathrm{sb}+\mathrm{lb} \rightarrow \mathrm{lb}}^{\prime \prime \prime}=\mathrm{K}_{\mathrm{sb}+\mathrm{lb} \rightarrow \mathrm{lb}} \varepsilon_{\mathrm{sb}} \varepsilon_{\mathrm{lb}} \\
\mathrm{K}_{\mathrm{sb}+\mathrm{lb} \rightarrow \mathrm{lb}}=\rho_{\mathrm{d}} \mathrm{P}_{\mathrm{sb}+\mathrm{lb} \rightarrow \mathrm{lb}} \omega_{\mathrm{sb}+\mathrm{lb} \rightarrow \mathrm{lb}} \\
\omega_{\mathrm{sb}+\mathrm{lb} \rightarrow \mathrm{lb}}=\frac{\left|\mathrm{v}_{\mathrm{sb}}-\mathrm{v}_{\mathrm{l}}\right| \mathrm{D}_{\mathrm{sb}}+\left|\mathrm{v}_{\mathrm{sb}}-\mathrm{v}_{\mid}\right| \mathrm{D}_{\mathrm{lb}}}{\pi\left(\mathrm{D}_{\mathrm{sb}}{ }^{2}+\mathrm{D}_{\mathrm{lb}}{ }^{2}\right)}
\end{gathered}
$$

For case 3, where small bubbles are stripped from the trailing rim or "skirt" of the large bubbles, the mass transfer rate is given as

$$
\begin{gathered}
\mathrm{m}_{\mathrm{lb} \rightarrow \mathrm{sb}}^{\prime \prime \prime}=\mathrm{K}_{\mathrm{lb} \rightarrow \mathrm{sb}} \varepsilon_{\mathrm{lb}} \\
\mathrm{K}_{\mathrm{lb} \rightarrow \mathrm{sb}}=\rho_{\mathrm{d}} \omega_{\mathrm{lb} \rightarrow \mathrm{sb}} \varepsilon_{\mathrm{lb}}
\end{gathered}
$$

Here, the mass transfer rate per unit volume for large bubbles to form small bubbles depends strongly on the surface tension. It also depends upon the local turbulence level, and tends to increase with increasing energy dissipation rate. Taking into account both factors, as well as the effects of the inertial and buoyancy forces, the following expression was used for the frequency of large bubble breakup [10] 


$$
\omega_{\mathrm{lb} \rightarrow \mathrm{sb}}=\rho_{\mathrm{d}}\left(\frac{2 \sigma}{\rho_{\mathrm{c}}}\right)^{0.4} \frac{12\left|\mathrm{v}_{\mathrm{sb}}-\mathrm{v}_{\mathrm{l}}\right|^{0.2}}{\left(1-\frac{\rho_{\mathrm{d}}}{\rho_{\mathrm{c}}}\right) \mathrm{D}_{\mathrm{lb}}^{1.4}\left[\left(\frac{\mathrm{D}_{\mathrm{lb}}}{D_{\mathrm{sb}}}\right)^{3}-1\right]} .
$$

The bubble breakup process is a result of the interactions between the bubbles and turbulent eddies [12].

\subsection{Two-Phase Turbulence Submodel}

The turbulent contribution to the stress tensor of the continuous phase is modeled by a standard twoequation $\mathrm{k}-\varepsilon$ model consisting of transport equations for the turbulent kinetic energy, $\mathrm{k}_{\mathrm{t}}$, and its viscous dissipation rate, $\varepsilon_{\mathrm{t}}$, as

$$
\begin{gathered}
\varepsilon_{\mathrm{c}} \frac{\mathrm{Dk_{ \textrm {t } }}}{\mathrm{Dt}}=\nabla \cdot\left(\frac{\varepsilon_{\mathrm{c}} \nu_{\mathrm{c}}^{\tau}}{\sigma_{\mathrm{k}}} \nabla \mathrm{k}_{\mathrm{t}}\right)+\varepsilon_{\mathrm{c}} \rho_{\mathrm{c}} \mathrm{G}-\varepsilon_{\mathrm{t}} \\
\varepsilon_{\mathrm{c}} \frac{\mathrm{D} \varepsilon_{\mathrm{t}}}{\mathrm{Dt}}=\nabla \cdot\left(\frac{\varepsilon_{\mathrm{c}} \nu_{\mathrm{c}}^{\tau}}{\sigma_{\varepsilon}} \nabla \varepsilon_{\mathrm{t}}\right)+\varepsilon_{\mathrm{c}} \frac{\varepsilon_{\mathrm{t}}}{\mathrm{k}_{\mathrm{t}}} \rho_{\mathrm{c}} \mathrm{GC} C_{1 \alpha}-\mathrm{C}_{2 \alpha} \varepsilon_{\mathrm{t}}
\end{gathered}
$$

where $\varepsilon_{\mathrm{c}}$ is the void fraction of the continuous phase. The effective viscosity of the liquid component of the two-phase flow is given by $[13,14]$

$$
v_{\mathrm{c}}^{\tau}=v_{\mathrm{c}}^{\prime \prime \prime}+v_{\mathrm{c}}^{\mathrm{t}}+v_{\mathrm{C}}^{2 \phi}
$$

In these equations, the term $\mathrm{G}$ is the turbulence production rate due to effects other than shear, $v_{\mathrm{C}}^{\prime \prime \prime}$ is the

molecular kinematic viscosity of the liquid, $v_{c}^{t}=\frac{C_{\mu} k^{2}}{\varepsilon}$ is the turbulent shear-induced kinematic viscosity,

and $v_{c}^{2 \phi}=\sum_{k} C_{\mu b} D_{k} \alpha_{k}\left|v_{d, k}-v_{c}\right|$ is the bubble-induced kinematic viscosity proposed by Sato and

Sekoguchi [13]. The coefficients in Equations 18 through 20 are $\mathrm{C}_{\mu}=0.09, \mathrm{C}_{1 \alpha}=1.44, \mathrm{C}_{2 \alpha}=1.92, \sigma_{\mathrm{k}}=1.0, \sigma_{\varepsilon}$ $=1.3$, and $\mathrm{C}_{\mu \mathrm{b}}=1.2$. No turbulence model is used to calculate the velocity fields within the bubbles. The turbulence within the gas bubbles is assumed not to affect the liquid phase turbulence [15].

\subsection{Mechanistic Submodels for Interfacial Momentum Forces}

The key to making the multifluid ensemble-averaged method work is capturing the important interfacial transfer mechanisms for mass, momentum and energy [5]. Closure relations are needed to reintroduce the information that was lost as a result of averaging the conservation equations. These closure laws account for the sub-scale mass and momentum transfer between the various fields and phases. The closure models provide the functional form expected for the interfacial forces. However, local condition dependent coefficients are expected since the closure models are derived for ideal bubbly flow conditions and applied to churn-turbulent flows.

This section describes the mechanistic models for various interfacial momentum forces occurring in churn-turbulent flow. The sum of forces on the dispersed bubble fields is equal and opposite to that on the continuous liquid field.

$$
M_{c}^{i}=-\sum_{k} M_{d, k}{ }^{i}
$$


The interfacial interactions between the individual bubble fields are specified by mechanistic models for both drag and non-drag forces. A similar approach has been implemented by $[16,17]$. The interfacial momentum transfer force, $M_{d, k}{ }^{i}$, is partitioned into drag and nondrag components

$$
M_{d, k}^{i}=M_{d, k}{ }^{D}+M_{d, k}^{N D}
$$

where

$$
M_{d, k}{ }^{N D}=M_{d, k}{ }^{L}+M_{d, k}{ }^{W}+M_{d, k}{ }^{T D}+M_{d, k}{ }^{V M}
$$

The interfacial momentum transfers considered important for churn-turbulent flows include the interfacial drag force as well as interfacial non-drag forces consisting of the lift force, the wall force, the turbulence dispersion force and the virtual mass force. Other forces, such as the Basset force, may also be present but are small and therefore neglected here.

The interfacial drag force is written as

$$
M_{d, k}^{D}=-\frac{1}{8} C_{D, k} \rho_{C}\left|v_{d, k}-v_{c}\right|\left(v_{d, k}-v_{c}\right) A_{i, k}^{\prime \prime} \frac{r_{s m, k}}{r_{d}}
$$

where the subscript $\mathrm{c}$ denotes the continuous field and d denotes the dispersed field (i.e., the bubbles). The ensemble-averaged fluid velocity of field-k is $\underline{v}_{k}$, the local volume fraction is $\alpha_{k}$, and the density is $\rho_{\mathrm{k}}$. The interfacial area density $\mathrm{A}_{\mathrm{i}, \mathrm{k}}^{\prime \prime \prime}$ is modeled assuming a spherical dispersed phase as

$$
A_{i, k}^{\prime \prime \prime}=f_{k} \frac{6 \varepsilon_{k}}{D_{k}} .
$$

The interfacial area density can be modified by a shape factor, $f_{k}$, to account for the nonspherical shape of the bubbles [18]. In Equation 24, the Sauter mean radius is given as

$$
r_{s m, k}=\frac{3 \forall_{k}}{A_{i, k}^{\prime \prime}}
$$

and the drag radius is expressed as

$$
r_{\mathrm{d}, \mathrm{k}}=\frac{3 \forall_{\mathrm{k}}}{4 \mathrm{~A}_{\mathrm{k}}}
$$

In these equations, $\forall_{k}$ and $A_{k}$ are the bubble volume and projected area, respectively. The term $\frac{r_{s m, k}}{r_{d}}$ is 1.0 for small bubbles, whereas for large bubbles it is approximately 1.8. For the large cap bubbles, the surface area of a partial sphere is projected assuming a wake angle of $50^{\circ}$ (see [19]). The drag coefficient $\mathrm{C}_{\mathrm{D}, \mathrm{k}}$ for the small bubbles is expressed as [20]

$$
C_{D, k}=\frac{24}{\operatorname{Re}_{k}}\left(1+0.1 \operatorname{Re}_{k}^{0.75}\right)
$$

where

$$
\operatorname{Re}_{k}=\frac{D_{k} \rho_{c}\left(v_{d, k}-v_{c}\right)}{\mu_{m}}
$$

with a mixture viscosity defined as

$$
\mu_{\mathrm{m}}=\frac{\mu_{\mathrm{c}}}{1-\varepsilon_{\mathrm{d}}}
$$


where

$$
\varepsilon_{\mathrm{d}}=\sum_{\mathrm{k}} \varepsilon_{\mathrm{k}}
$$

The drag coefficient $C_{D}$ for the large cap bubbles is given as

$$
\mathrm{C}_{\mathrm{D}, \mathrm{k}}=\frac{8}{3}\left(1-\varepsilon_{\mathrm{k}}\right)^{2}
$$

For simplicity, the bubbles are considered to be rigid spheres, although it is known that internal circulation within the bubbles can decrease the drag [21].

The effective dispersed phase diameter $D_{k}$ and the drag coefficient $C_{D, k}$ are input by the user. The drag forces on the bubbles oppose the direction of liquid flow. The forces acting in the axial direction include drag, gravity and buoyancy.

The interfacial lift force accounts for the lateral forces between the dispersed and continuous phase due to aerodynamic lift and is expressed as

$$
\mathrm{M}_{\mathrm{d}, \mathrm{k}}{ }^{\mathrm{L}}=-\mathrm{C}_{\mathrm{L}, \mathrm{k}} \rho_{\mathrm{C}} \varepsilon_{\mathrm{k}}\left(\mathrm{v}_{\mathrm{d}, \mathrm{k}}-\mathrm{v}_{\mathrm{c}}\right) \times\left(\nabla \times \mathrm{v}_{\mathrm{c}}\right)
$$

The lift force is due to the velocity gradients in the continuous field. The approach for determining the lift force is similar to that employed by [16]. The lift force coefficient is based upon the correlation for polydispersed flows given by [22]

$$
C_{L, k}=\left\{\begin{array}{lr}
\min \left(0.288 \tanh \left(0.121 \operatorname{Re}_{\mathrm{k}}\right), \mathrm{f}\left(\mathrm{Eo}_{\mathrm{k}}\right)\right) & \mathrm{Eo}_{\mathrm{k}}<4 \\
\mathrm{f}\left(\mathrm{Eo}_{\mathrm{k}}\right) & 4<\mathrm{Eo}_{\mathrm{k}}<10 \\
-0.27 & \mathrm{Eo}_{\mathrm{k}}>10
\end{array}\right.
$$

with

$$
\mathrm{f}\left(\mathrm{Eo}_{\mathrm{k}}\right)=0.00105 \mathrm{Eo}_{\mathrm{k}}^{3}-0.0159 \mathrm{Eo}_{\mathrm{k}}^{2}-0.0204 \mathrm{Eo}_{\mathrm{k}}+0.474
$$

where $\mathrm{Eo}_{\mathrm{k}}$ is the Eötvös number calculated as

$$
E o_{k}=\frac{g\left(\rho_{c}-\rho_{d}\right) D_{h, k}^{2}}{\sigma}
$$

The Eötvös number is proportional to the buoyancy force divided by the surface tension force and, together with the Morton number and Reynolds number, can be used to characterize the shape of bubbles moving in a surrounding fluid. Such flow regime maps are given by Clift et al. [21]. An empirical correlation [23] for aspect ratio of an elliptical shape bubble is used to calculate the maximum horizontal dimension of the bubble, $\mathrm{D}_{\mathrm{h}, \mathrm{k}}$

$$
D_{h, k}=D_{k} \sqrt[3]{1+0.163 \mathrm{Eo}_{k}^{0.757}}
$$

since the maximum vertical dimension of the bubble is expressed as [17]

$$
D_{v, k}=\frac{D_{k}^{3}}{D_{h, k}^{2}}
$$

The lift force acts on the bubbles in a direction perpendicular to the bulk flow when gradients of liquid velocity are present. It acts in a similar manner to that of an asymmetric airfoil in a uniform flow, but rather is a result of a non-uniform velocity field moving over a symmetric bubble. The effect is to move the bubbles towards or away from the pipe wall. The critical bubble diameter [24] at which the lift 
force changes sign can be found by solving for the roots of Equation 35. According to the Tomiyama correlation, bubbles with a diameter smaller than the critical diameter are given a positive lift force coefficient, whereas bubbles with a diameter larger than the critical diameter are given a negative lift force coefficient. The negative lift force coefficient causes the large bubbles to migrate towards the center of the pipe for the case of co-current upward vertical pipe flow. Conversely, the smaller bubbles tend to move towards the wall. Note that if the flow direction was reversed (i.e., co-current downward flow), the behavior would be opposite.

The interfacial wall force accounts for the hydrodynamic force on a bubble traveling in close proximity to a solid wall and is expressed as

$$
\mathrm{M}_{\mathrm{d}, \mathrm{k}}{ }^{\mathrm{w}}=-\mathrm{C}_{\mathrm{W}, \mathrm{k}} \mathrm{F}(\eta) \frac{2 \varepsilon_{\mathrm{k}} \rho_{\mathrm{c}}\left|\mathrm{v}_{\mathrm{d}, \mathrm{k}}-\mathrm{v}_{\mathrm{c}}\right|^{2}}{\mathrm{D}_{\mathrm{k}}} \underline{\mathrm{n}}
$$

where

$$
\eta=\frac{2 y}{c_{\eta} D_{k}}
$$

In the preceding equations, $\mathrm{y}$ is the distance between the bubble and the wall and $\underline{\mathrm{n}}$ is the outward normal vector at the surface of the wall. Due to the non-uniform drainage of the liquid around the bubble, a lateral lubrication-like force caused by surface tension pushes the bubbles away from the wall. The multiphase wall force only acts in a localized region adjacent to the pipe wall. The term $\mathrm{c}_{\eta}$ adjusts this region of influence and was set to 0.7 . The wall force distance function $F(\eta)$ is given as [10]

$$
F(\eta)=\left(\begin{array}{ll}
1+\left(\frac{\eta}{2}\right)^{2}(\eta-3) & \text { for } y<D_{k} \\
0.0 & \text { for } y \geq D_{k}
\end{array}\right.
$$

The effect of the wall force is seen as a sharp spike in bubble void fraction near the wall that affects the small bubbles.

To account for the increased mixing due to turbulence in a two-phase flow, a turbulence volume fraction dispersion force is included. The turbulent dispersion force depends on the magnitude of turbulence in the liquid phase and the gradient of the volume fraction [25]

$$
\mathrm{M}_{\mathrm{d}, \mathrm{k}}^{\mathrm{TD}}=-\mathrm{C}_{\mathrm{TD}, \mathrm{k}} \rho_{\mathrm{c}} \mathrm{k} \nabla \varepsilon_{\mathrm{k}}
$$

In this submodel, the turbulent dispersion force serves to transport the gaseous phase in a direction opposing the void fraction gradient. For isotropic turbulence, the turbulent dispersion coefficient $\left(\mathrm{C}_{\mathrm{TD}}\right)$ is assigned a value of $2 / 3$. Accounting for the effect of anisotropy (due to higher velocity fluctuations in the axial than in the radial direction) lowers the turbulent dispersion coefficient to $1 / 2$ [5]. The forces acting in the radial direction include lift, wall and turbulent dispersion forces.

The virtual mass force occurs when a bubble accelerates through the liquid and is given by

$$
\mathrm{M}_{\mathrm{d}, \mathrm{k}}^{\mathrm{VM}}=-\mathrm{C}_{\mathrm{VM}, \mathrm{k}} \rho_{\mathrm{c}} \varepsilon_{\mathrm{k}}\left\{\left[\frac{\partial \mathrm{v}_{\mathrm{d}, \mathrm{k}}}{\partial \mathrm{t}}+\left(\mathrm{v}_{\mathrm{d}, \mathrm{k}} \cdot \nabla\right) \mathrm{v}_{\mathrm{d}, \mathrm{k}}\right]-\left[\frac{\partial \mathrm{v}_{\mathrm{c}}}{\partial \mathrm{t}}+\left(\mathrm{v}_{\mathrm{c}} \cdot \nabla\right) \mathrm{v}_{\mathrm{c}}\right]\right\}
$$

The virtual mass force is due to the inertia of the continuous phase mass encountered by the accelerating droplets. The virtual mass coefficient, $\mathrm{C}_{\mathrm{VM}, \mathrm{k}}$, is specified by the user. For these simulations $\mathrm{C}_{\mathrm{VM}, \mathrm{k}}$ was set to 0.5 . The virtual mass force applied in this steady-state simulation is expected to be small and serves mainly to stabilize the numerical solution by limiting the change in gas velocity. 


\section{Model Testing and Validation}

Figure 1 illustrates the various levels of model testing and validation necessary before the model can be used for high-fidelity simulations. The steps in this hierarchy consist of

1. Basic physics involved in the hydrodynamics and chemical reaction processes, such as turbulent fluid mechanics, heat transfer, bubble breakup and coalescence, detailed reaction chemistry, etc.

2. Various numerical submodels describing the controlling physics

3. Bench-scale and pilot-scale testing results, which support full-scale plant testing and application.

The manner in which the validation hierarchy is developed starts at the most comprehensive level (plantscale application) and works downward through each subsection to establish a detailed understanding of the complete process(es) involved as the physical process is simulated.

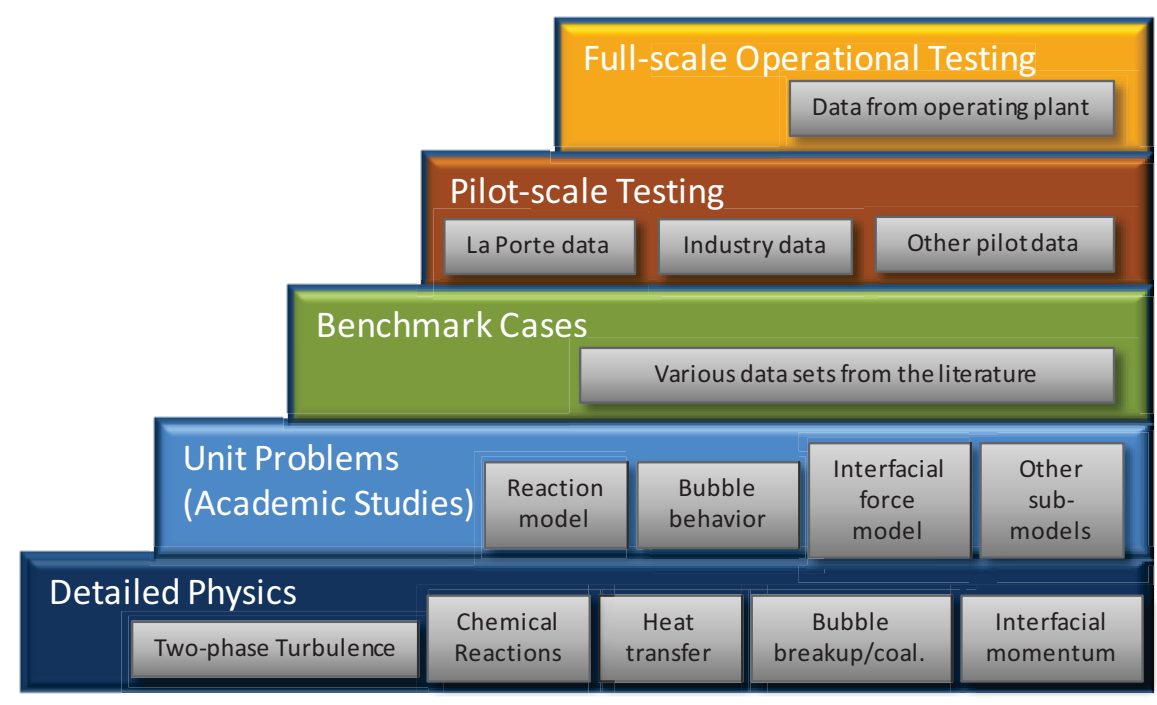

Figure 1. Model testing and validation hierarchy.

A partial validation of the CMFD model was performed to confirm the validity of the hydrodynamic simulations without chemistry [26]. Computational simulations of upward, co-current adiabatic air-water flow in a vertical pipe are compared to high-quality experimental data from the Transient twO Phase FLOW test facility (TOPFLOW) at the Institute of Safety Research at the Forschungszentrum DresdenRossendorf [8]. Two cases were selected from the TOPFLOW experiment database with two-phase flow in the churn-turbulent flow regime. The bulk liquid mass flow rate is $30.336 \mathrm{~kg} / \mathrm{s}$ for both cases with an inlet liquid superficial velocity of $1.017 \mathrm{~m} / \mathrm{s}$. The two TOPFLOW cases are identical except for the inlet gas velocity. The inlet superficial gas velocities $j_{\mathrm{g}}$ for Cases 118 and 140 are $0.22 \mathrm{~m} / \mathrm{s}$ and $0.53 \mathrm{~m} / \mathrm{s}$, respectively. A constant gas density was assigned corresponding to an outlet pressure of $176.7 \mathrm{kPa}$ and $188.5 \mathrm{kPa}$ for Cases 118 and 140, respectively.

The TOPFLOW data is arranged into four groups based upon bubble diameter, i.e., $\mathrm{D}_{\mathrm{b}}<5.8 \mathrm{~mm}$, $5.8 \mathrm{~mm} \leq \mathrm{D}_{\mathrm{b}}<7.0 \mathrm{~mm}, 7.0 \mathrm{~mm} \leq \mathrm{D}_{\mathrm{b}}<10.0 \mathrm{~mm}$, and $10.0 \mathrm{~mm} \leq \mathrm{D}_{\mathrm{b}} \leq 200 \mathrm{~mm}$. The smallest size bubble that can be measured by the wire mesh sensor in the TOPFLOW experiments is approximately $2 \mathrm{~mm}$. The largest bubble size is constrained by the pipe inner diameter. Table 2 lists the inlet void fraction, inlet velocity and mean bubble size specified for the five fields (continuous liquid plus four bubble groups) in the simulations. The mean bubble size corresponds to the TOPFLOW bubble size groups. For simplicity, uniform inlet velocity and void fraction distribution were applied at the inlet. 
The CMFD simulation replicated the experimental conditions for air-water flow in a vertical pipe with an inside diameter of $195.3 \mathrm{~mm}$. Computed profiles were compared to experimental data at a pipe length equal to 40 pipe diameters. Figures 2 through 5 compare the radial distribution of void fraction for fields 2, 3, 4 and 5 predicted by the NPHASE-CMFD code to those obtained in the TOPFLOW experiments for Cases 118 and 140.

\begin{tabular}{|c|c|c|c|c|c|}
\hline \multirow{2}{*}{$\begin{array}{c}\text { Field } \\
\qquad k\end{array}$} & \multirow{2}{*}{$\begin{array}{c}D_{k} \\
(\mathrm{~mm})\end{array}$} & \multicolumn{2}{|c|}{$\begin{array}{c}\text { Case } 118 \\
j_{l}=1.017 \mathrm{~m} / \mathrm{s}, j_{g}=0.22 \\
\mathrm{~m} / \mathrm{s}\end{array}$} & \multicolumn{2}{|c|}{$\begin{array}{c}\text { Case } 140 \\
j_{l}=1.017 \mathrm{~m} / \mathrm{s}, j_{g}=0.53 \\
\mathrm{~m} / \mathrm{s}\end{array}$} \\
\hline & & $\begin{array}{c}\alpha \\
(\%) \\
\end{array}$ & $\begin{array}{c}v \\
(\mathrm{~m} / \mathrm{s}) \\
\end{array}$ & $\begin{array}{c}\alpha \\
(\%)\end{array}$ & $\begin{array}{c}v \\
(\mathrm{~m} / \mathrm{s})\end{array}$ \\
\hline 1 & N/A & 76.0 & 1.3 & 58.2 & 1.68 \\
\hline 2 & 3.9 & 3.8 & 1.3 & 2.5 & 1.68 \\
\hline 3 & 6.4 & 2.5 & 1.3 & 2.0 & 1.68 \\
\hline 4 & 8.5 & 5.8 & 1.3 & 6.1 & 1.68 \\
\hline 5 & 15. & 11.9 & 1.3 & 31.2 & 1.68 \\
\hline
\end{tabular}

An axisymmetric $40 \times 500$ grid with refined cell size of $0.5 \mathrm{~mm}$ near the wall was used to represent the $0.09765 \mathrm{~m} \times 9.66 \mathrm{~m}$ domain. There are 40 nodes along the radial axis and 500 axial nodes. Taking advantage of symmetry, half of the pipe was modeled. At the wall boundary, the no slip condition was invoked. A symmetry boundary condition was employed along the pipe centerline. The inlet was modeled as a velocity inlet and at the pipe exit a constant pressure boundary condition was applied. The mesh spacing is finer near the inlet to capture the developing flow. A grid study was performed to verify that the results obtained are grid independent.

The void fraction of the smallest bubble size group (Field 2) is seen to peak a small distance away from the wall (Figure 2). This effect diminishes as bubble size increases (Figures 3 and 4). The measured radial void fraction distributions for the smaller bubbles show a characteristic peak near the wall. The small bubbles gravitate to the wall, whereas the large bubbles move towards the center of the pipe. The local peaking of the void fraction near the wall for the small bubbles is caused by the lift force that directs the small bubbles towards the wall interacting with the wall force that pushes the bubbles away from the wall. To numerically obtain radial void fraction distributions similar to those measured experimentally, it is necessary to specify a positive lift force coefficient for bubble groups 2, 3 and 4 and a negative lift force coefficient for bubble group 5. Note that if the water flow in the pipe was directed downwards, both the lift and wall forces for the small bubbles would be directed towards the center of the pipe and peaking of the void fraction would not occur near the wall [27].

In Figure 5 it is seen that the largest bubble group (Field 5 in the model) exhibits a Gaussian-shaped void fraction distribution with a maximum near the center of the pipe. For all cases, the void fraction approaches zero at the wall. The TOPFLOW data show an increase in void fraction (also called gas holdup) at higher gas injection flow rates. This effect has also been observed for air-water flow in bubble columns operating in the churn-turbulent regime[28].

Figure 6 compares the computed and measured nearly fully developed radial gas velocity profile. The nearly fully developed average gas velocity is higher for Case 140 than Case 118, since the gas injection velocity is higher. The radial velocity distribution for all four bubble fields predicted by the model is shown along with an average velocity for all bubble fields. The experimental data averages all the bubble fields (i.e., size groups). The model predicts that the larger bubbles travel faster than the smaller bubbles. The large bubbles appear to be driving the flow, dragging the smaller bubbles along [29]. This occurs since the drag force increases with decreasing bubble size. 
The Tomiyama correlation (Equation 34) provides a reasonable estimate for the lift force coefficient for bubble groups 2, 3 and 5. However, the correlation predicts a negative lift force coefficient for bubble group 4 (bubble diameters between 5.8 and $7.0 \mathrm{~mm}$,) since the predicted critical spherical bubble diameter is $5.8 \mathrm{~mm}$. The TOPFLOW data shown in Figures 1 to 4 are based upon a sphere equivalent diameter. The data exhibit a wall peak and a generally positive slope in the radial profile for bubble group 4 . Several possible reasons for this discrepancy in critical bubble diameter are proposed. The correlation was obtained from experimental investigations on single bubbles in laminar flow in a water-glycerol solution. The TOPFLOW data were obtained for a turbulent air-water flow with a polydisperse bubble distribution. A continual process of bubble breakup and coalescence occurs in the flow due to a shearing of small bubbles from the larger bubbles and, at the same time, a coalescence of the smaller bubbles. This coalescence rate increases with the square of the bubble number density. Since the lift force moves the small bubbles to form a wall peak, the coalescence rate of the small bubbles is highest near the wall (i.e., there is a source for bubbles of group 4 in the near wall region). If it is assumed that the Tomiyama correlation is valid for TOPFLOW conditions, these bubbles should migrate towards the pipe center, where they coalesce to form larger bubbles. Correspondingly, even in case of a negative lift force coefficient for bubble group 4, a profile with a wall peak may be established due to the near wall source and the sink for this bubble group in the center. Another possible reason is bubble-bubble interaction. The large bubbles move upwards at a faster velocity than the small bubbles and this motion pushes the small bubbles away from the center of the pipe. It appears from the flattening radial void fraction profile of bubble group 4 for Case 118 that these competing processes are almost balanced. For the group 4 bubbles of Case 140, the radial void fraction profile is wall peaked. The higher gas flow rate causes higher shear forces that strip small bubbles from the larger ones. The larger momentum of the large bubbles pushes the small bubbles towards the wall and creates the wall peak shape of the radial void fraction profile. The transition from wall to core peaking takes place at a smaller critical bubble size for the lower superficial gas injection velocity.
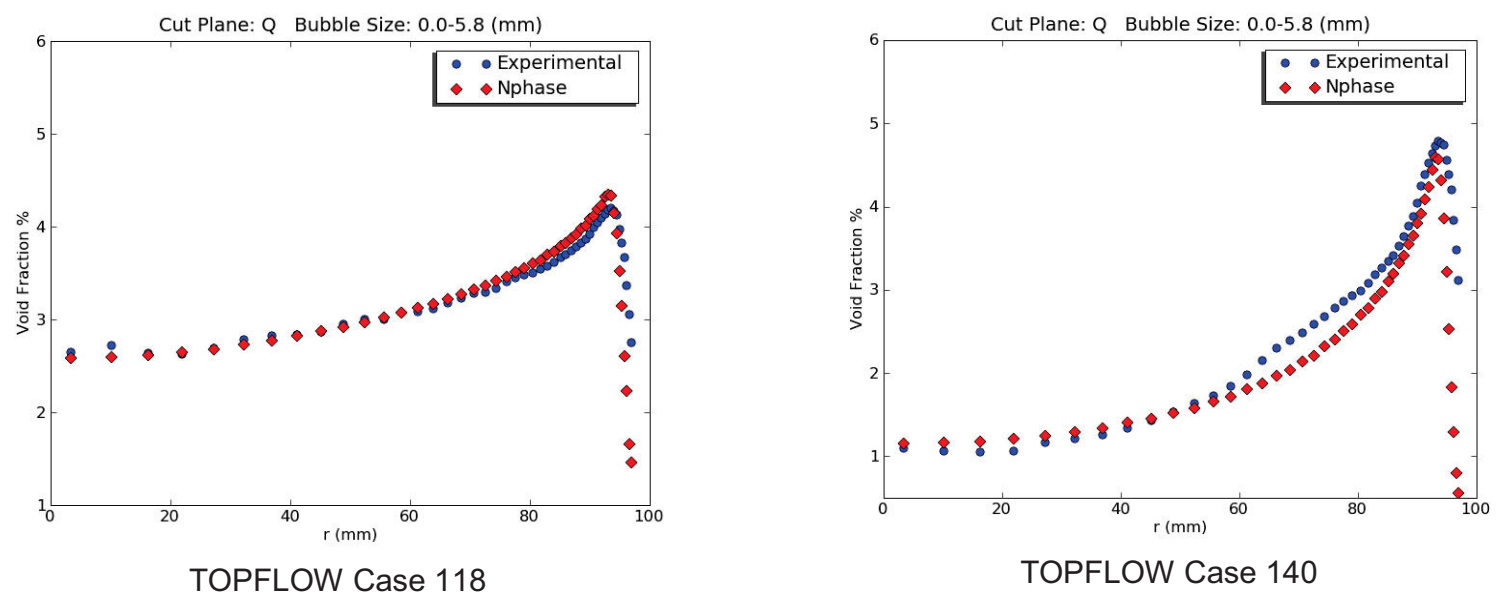

Figure 2. Comparison of Field 2 computed vs. experimental radial void fraction distribution for $\mathrm{D}_{\mathrm{b}}<5.8 \mathrm{~mm}$. 

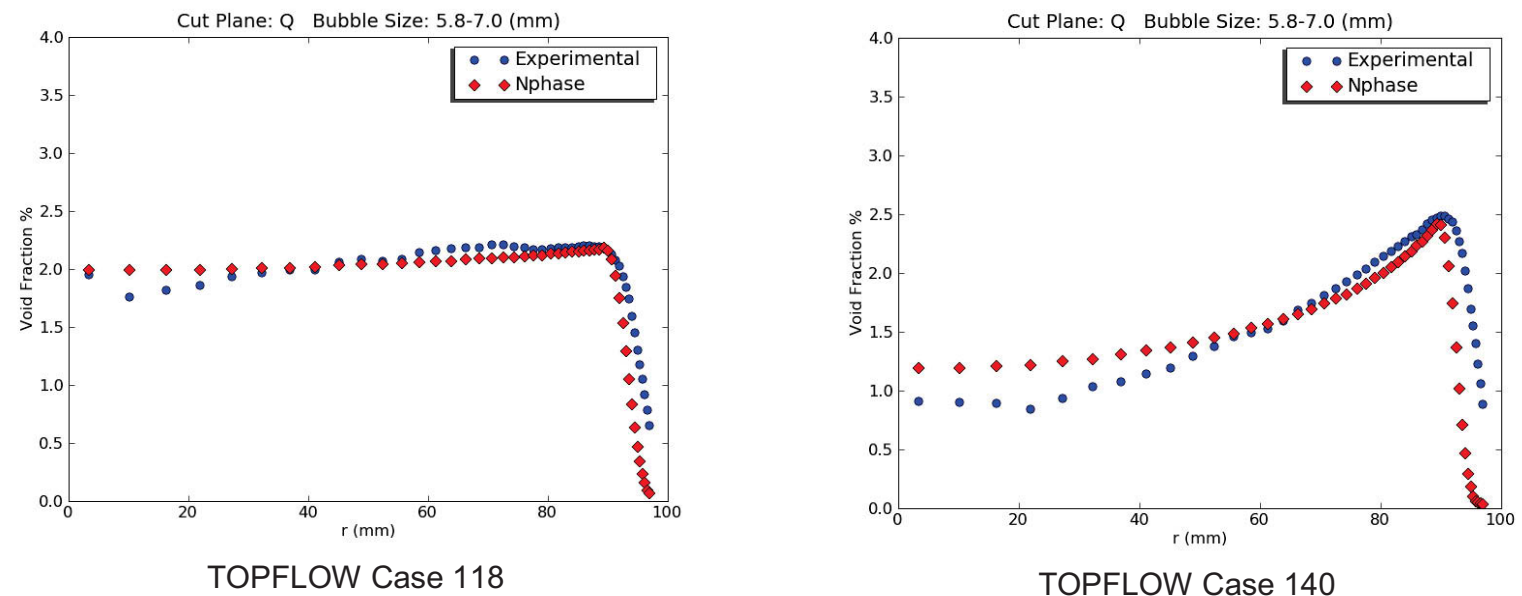

Figure 3. Comparison of Field 3 computed vs. experimental radial void fraction distribution for $5.8 \mathrm{~mm} \leq \mathrm{D}_{\mathrm{b}}<7.0 \mathrm{~mm}$.
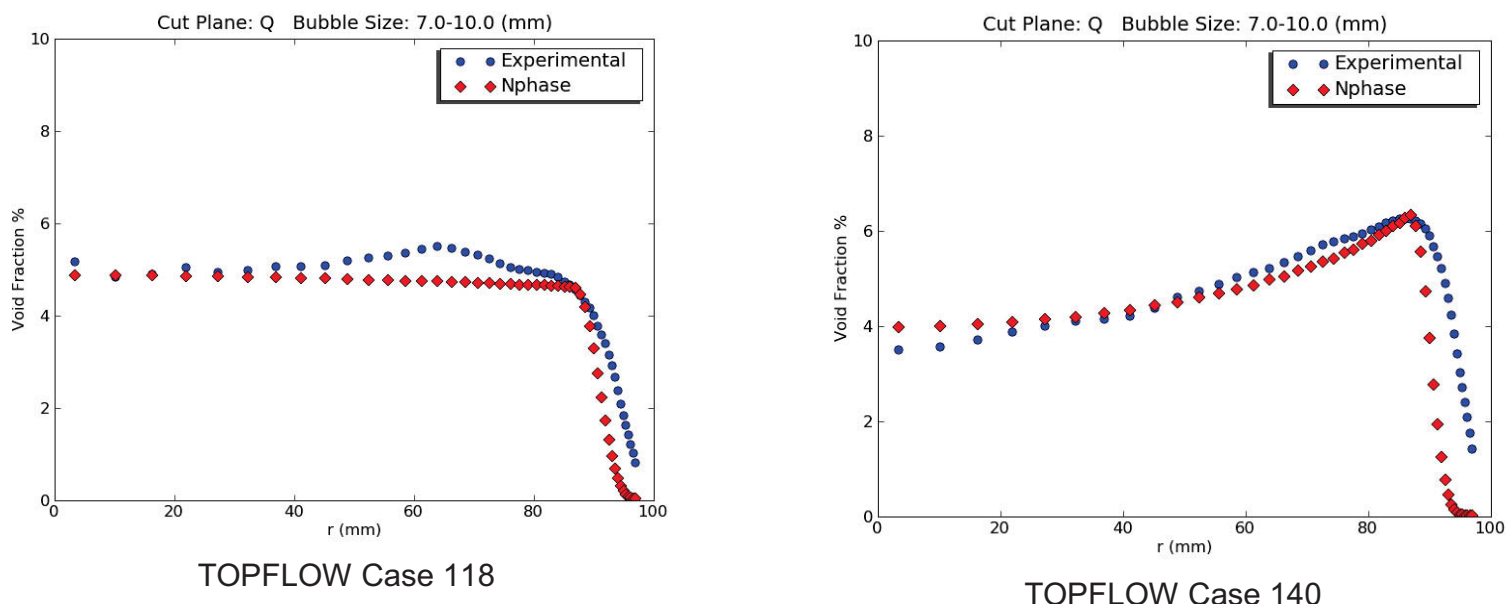

Figure 4. Comparison of Field 4 computed vs. experimental radial void fraction distribution for $7.0 \mathrm{~mm} \leq \mathrm{D}_{\mathrm{b}}<10.0 \mathrm{~mm}$.
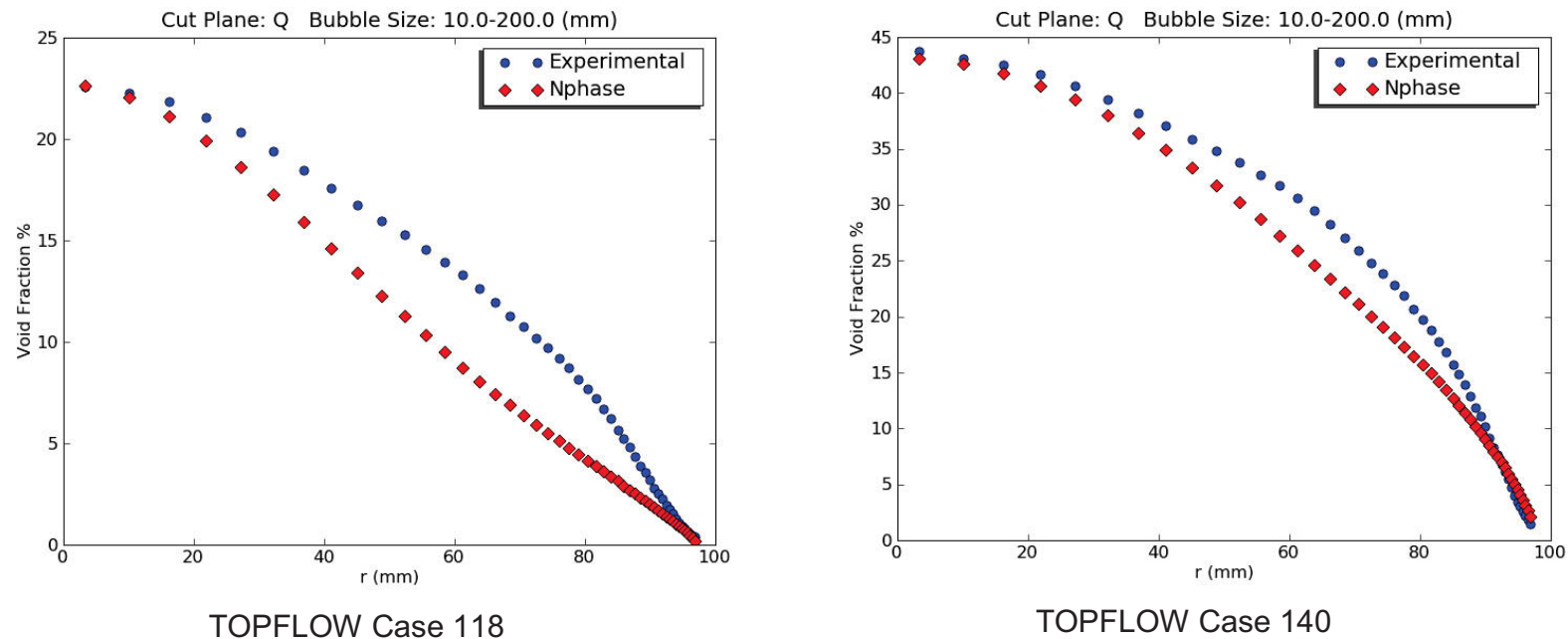

Figure 5. Comparison of Field 5 computed vs. experimental radial void fraction distribution for $10.0 \mathrm{~mm} \leq \mathrm{D}_{\mathrm{b}} \leq 200 \mathrm{~mm}$. 


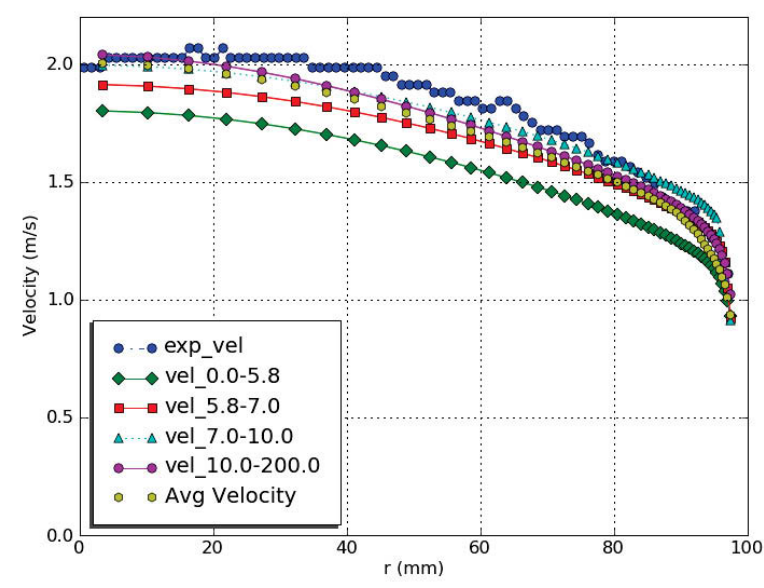

TOPFLOW Case 118

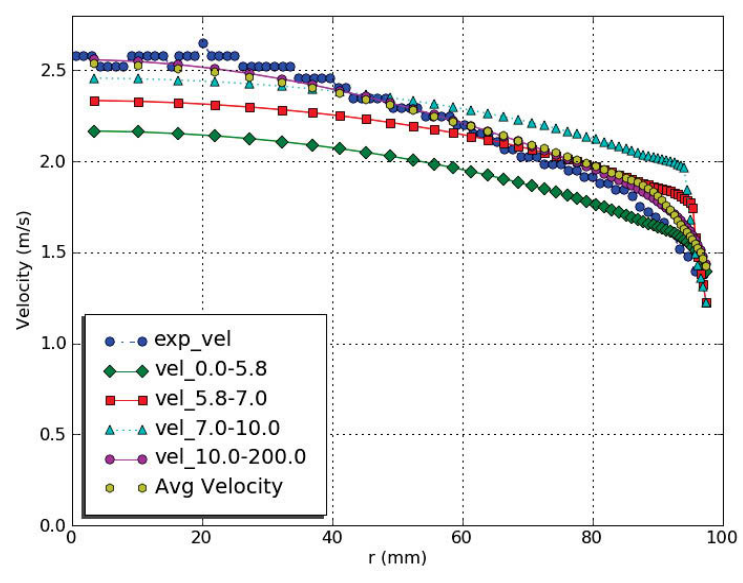

TOPFLOW Case 140

Figure 6. Comparison of computed vs. experimental gas velocity radial distribution.

\section{Property Method Approach}

FT synthesis produces a product stream characterized by a light hydrocarbon fraction $\left(\mathrm{C}_{1}-\mathrm{C}_{4}\right)$, a gasoline fraction $\left(\mathrm{C}_{5}-\mathrm{C}_{11}\right)$, a diesel fraction $\left(\mathrm{C}_{12}-\mathrm{C}_{19}\right)$ and a wax fraction $\left(\mathrm{C}_{20+}\right)$ as its main products, with water and carbon dioxide as by-products. A cobalt catalyst was selected for the initial model since, unlike Fe catalysts, cobalt-based catalysts exhibit very little water-gas-shift (WGS) activity. Due to the minimal WGS activity, the by-product is mostly water.

To simplify the model, the FT product distribution is characterized by a representative liquid hydrocarbon (HC) product, a representative $\mathrm{HC}$ vapor product and water/steam. This results in modeling 13 species consisting of

- CO reactant in small bubbles, large bubbles, and the bulk fluid

- $\mathrm{H}_{2}$ reactant in small bubbles, large bubbles, and the bulk fluid

- HC wax product in small bubbles, large bubbles, and the bulk fluid, and

- $\mathrm{H}_{2} \mathrm{O}$ product in small bubbles, large bubbles, and the bulk fluid, and

- Catalyst in bulk fluid.

The local mass fractions of the chemical species are tracked using 13 separate species transport equations. The mass fraction is tracked for the species $\mathrm{H}_{2}$ and $\mathrm{CO}$ in the gas phase and $\mathrm{HC}$ and $\mathrm{H}_{2} \mathrm{O}$ in the liquid and vapor phases. Absorption of gas species from both large and small bubbles into the bulk liquid phase is included. The driving force for the gas across the bubble interface into the bulk liquid will be dependent upon the interfacial species concentration in both small and large bubbles. However, because it is difficult to measure the concentration at the gas-liquid interface, coefficients for convective mass transfer across an interface for the overall driving force between the bulk concentrations in the gas and liquid phases are implemented. The product from the incorporation of absorption is the steady state concentration profile of the absorbed gas species in the bulk liquid phase and the impact of the hydrodynamics on the concentration profile.

VLE properties are computed using a chemical process simulation package (Aspen Plus from Aspen Technology, Inc.). Aspen Plus uses properties from DIPPR and other property databanks, which facilitates property validation. Using Aspen Plus, a heater block was created, which allows the 
temperature and pressure of the hydrocarbon stream exiting the FT reactor to be varied. The PengRobinson thermodynamics package is used. The hydrocarbon product stream is then sent to a flash drum where it is separated into vapor and liquid streams. A sensitivity operation is used to calculate the various thermodynamic and physical properties for the liquid and vapor streams, as well as the vapor fraction exiting the heater block. Then, based on the temperature and pressure, the appropriate split between liquid and vapor products can be calculated and the associated properties using the equations regressed from the data. Depending upon the temperature and pressure of the operating column, $\mathrm{H}_{2} \mathrm{O}$ may experience a phase change and both liquid and vapor are present.

This methodology provides reactant and product properties that are functions of reactor temperature and pressure. The expressions have the general form

$$
\phi(T, P)=\xi_{1} T P+\xi_{2} P^{2}+\xi_{3} P+\xi_{4}+\xi_{5} T+\xi_{6} T^{2}
$$

where $\phi(T, P)$ represents a physical quantity (such as molecular weight, density, viscosity, etc.). It is necessary to retain a sufficient number of significant figures (at least 14) to minimize the amount of error. Contours of the property surfaces for the hydrocarbon liquid and vapor densities are shown in Figure 7. The property surfaces for the calculated physical and thermodynamic properties show a smooth variation. All physical properties are calculated based on temperature and pressure of the current computational cell. All properties are in SI units, pressure is in $\mathrm{Pa}$ and temperature is in $\mathrm{K}$ for all equations listed, unless otherwise noted. The property equations derived by regression from the Aspen Plus simulation results are valid over a temperature range from 423 to $623 \mathrm{~K}$ and a pressure range from 2.4 to $3.4 \mathrm{MPa}$.
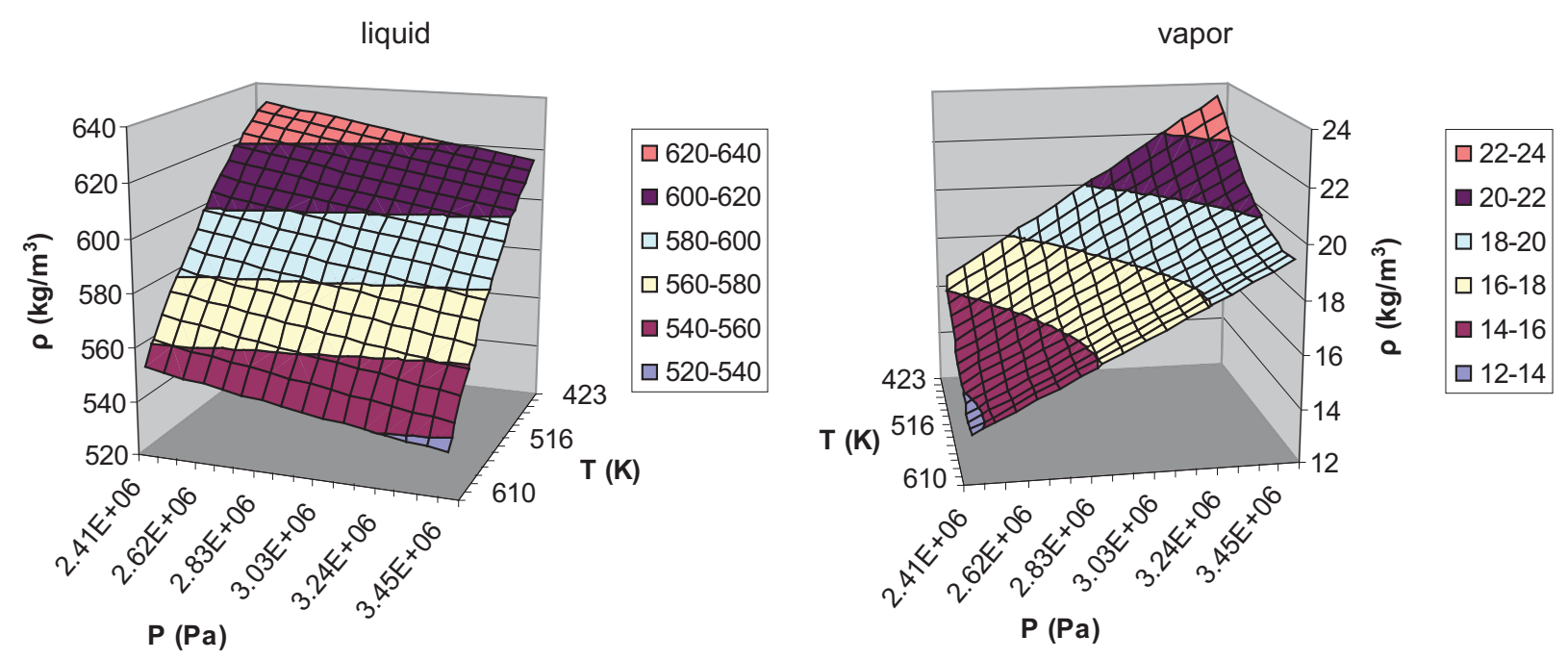

Figure 7. Property surface for hydrocarbon density.

The trick to making the property method approach work with the CMFD code is to stabilize the solution by referencing the hydrodynamic pressure. If the local system pressure is used for the properties, initial instabilities in the calculation as convergence is approached are amplified causing the CMFD simulation to diverge. For this reason, the hydrodynamic pressure (a function of column height) is used in the equations for the various reactant and product properties. As shown in Equation 40, the CMFD code uses enthalpy, rather than temperature. A subroutine to derive local temperature from enthalpy and specific heat was written, since the property expressions use temperature whereas the CFMD code uses enthalpy. Expressions for the properties are then connected to the main NPHASE-CMFD solver via user- 
defined subroutines. This approach allows the incorporation of VLE without all the added baggage of doing complex, time-consuming calculations within the CMFD code.

The procedure employed by the property method approach is described in detail below and depicted graphically in Figure 8.The VLE simulation performed in Aspen is used to obtain equations for the various physical and thermodynamic properties and parameters. The CMFD solution is initialized with a set of initial conditions. The initial temperature and pressure are provided to the routines indicated by "FT reactions." The results of these routines includes: (1) properties, (2) the mass transfer source term, and (3) the species source term, which are used by the CMFD code. The CMFD results are checked for convergence. If the solution has converged within an acceptable residual, the spatial distribution of velocity, temperature, pressure, phase hold-up and species within the SBCR are output. If not, the updated temperature and pressure are used in the "FT reactions" routines and the CMFD code iterates until convergence within a specified tolerance is achieved.

\section{Step 1: Calculate properties for liquid hydrocarbon}

First, determine the physical properties of the bulk liquid hydrocarbon using calculated regression coefficients. This liquid hydrocarbon product represents the entire spectrum of liquid hydrocarbons produced by the chemical reactions (i.e., from $\mathrm{C}_{5}$ and above).

\section{Step 2: Calculate properties of gas bubble mixture}

Next, determine the physical properties of the large and small bubble mixtures using the corresponding regression coefficients. To calculate the mixture properties of the gas in the bubbles, multiply the pure $\mathrm{CO}$ and $\mathrm{H}_{2}$ physical properties by their corresponding mol\% and sum the results as outlined in Equations 46 and 47.

The mass fraction, $\mathrm{Y}_{\mathrm{s}}$, is related to the molar concentration $\mathrm{c}_{\mathrm{s}}\left(\right.$ moles $\left./ \mathrm{m}^{3}\right)$ of species $\mathrm{s}$ by

$$
Y_{\mathrm{s}}=\frac{\mathrm{MW}_{\mathrm{s}} \mathrm{c}_{\mathrm{s}}}{\rho_{\mathrm{k}}}
$$

where $\mathrm{MW}_{\mathrm{s}}(\mathrm{kg} / \mathrm{mole})$ is the molecular weight for species, $\mathrm{s}$. Gas mixture properties are calculated by the mixture rule

$$
\phi_{\text {mix,k }}(T, P)=\sum_{s} \phi_{s, k}(T, P) Y_{s, k}
$$

where the terms are summed over the number of gaseous species. For the initial gas mixture comprised of only $\mathrm{CO}$ and $\mathrm{H}_{2}$, the expression for the small bubble (sb) field is

$$
\phi_{\text {mix }, \mathrm{sb}}(\mathrm{T}, \mathrm{P})=\phi_{\mathrm{CO}, \mathrm{sb}}(\mathrm{T}, \mathrm{P}) \mathrm{Y}_{\mathrm{CO}, \mathrm{sb}}+\phi_{\mathrm{H} 2, \mathrm{sb}}(\mathrm{T}, \mathrm{P}) \mathrm{Y}_{\mathrm{H} 2, \mathrm{sb}}
$$

and, similarly, for the large bubble (lb) field

$$
\phi_{\text {mix,lb }}(T, P)=\phi_{C O, l b}(T, P) Y_{C O, l b}+\phi_{H 2, l b}(T, P) Y_{H 2, l b}
$$


where density, viscosity, specific heat, thermal conductivity and Prandtl number are substituted for the variable $\phi$. Once the syngas has reacted and gaseous hydrocarbon products and water vapor are produced, these additional components must be included in the mixture property calculation.

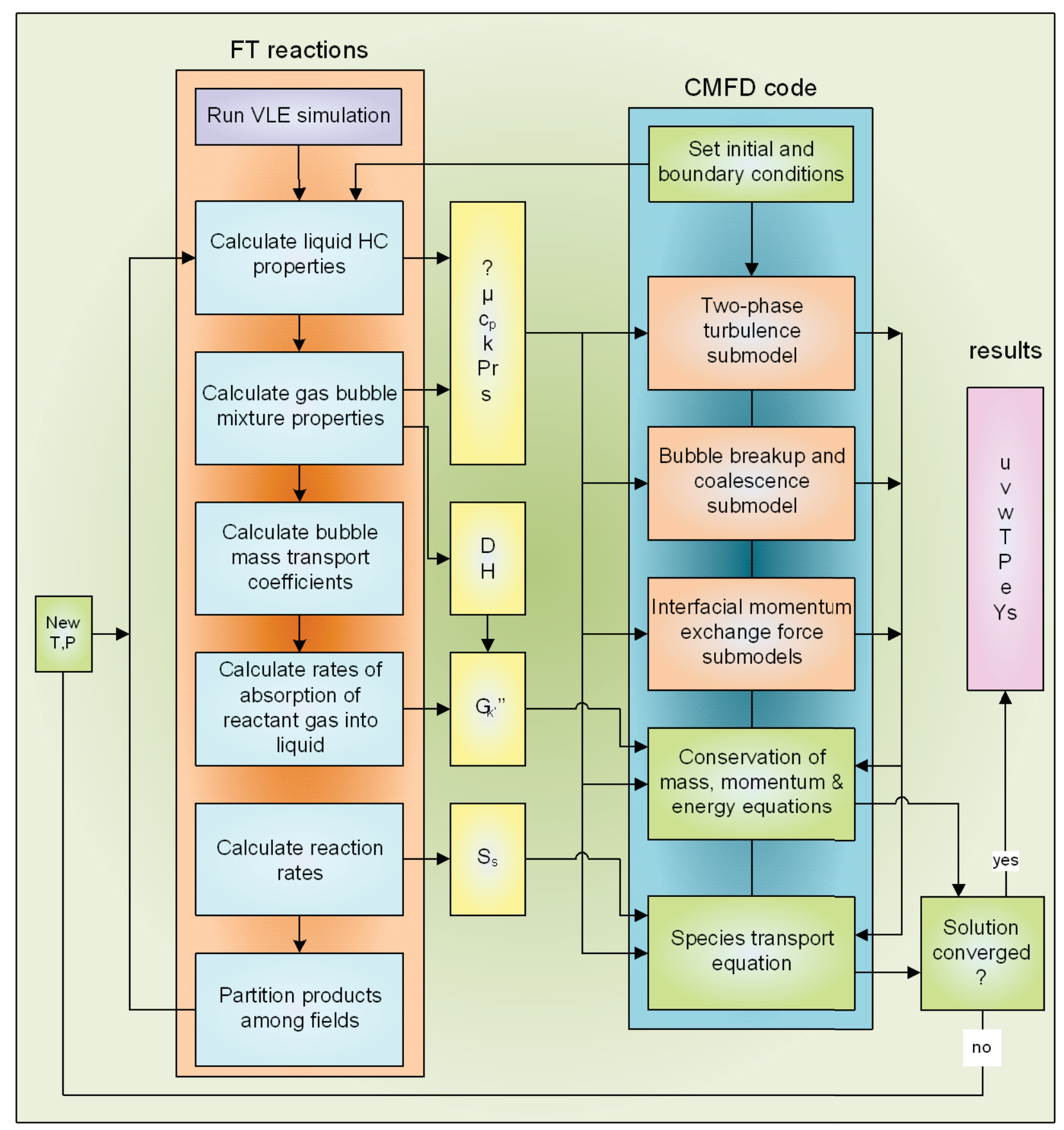

Figure 8. Incorporation of property method approach into solution methodology. 


\section{Step 3: Calculate small and large bubble mass transport coefficients}

After the initial physical properties are calculated for the wax and bubble mixtures, the mass transport rates and reaction rates are calculated as described in [30]. The mass transfer coefficient for large and small bubbles for each gas species is calculated based on the diffusion coefficients regressed from the Aspen Plus output. First, the diffusion coefficient is calculated for $\mathrm{CO}$ and $\mathrm{H}_{2}$ in the liquid hydrocarbon (wax) product, using the coefficient data for $\mathrm{CO}$ and $\mathrm{H}_{2}$.

Then, the volumetric mass transport coefficient for $\mathrm{CO}$ and $\mathrm{H}_{2}$ in small and large bubbles is calculated as a function of gas holdup and diffusivity [1]

$$
\begin{aligned}
& \frac{\mathrm{k}_{\mathrm{L}} \mathrm{a}_{\mathrm{s}, \mathrm{sb}}}{\varepsilon_{\mathrm{sb}}}=1.0 \sqrt{\frac{\mathrm{D}_{\mathrm{L}, \mathrm{s}}}{\mathrm{D}_{\mathrm{L}, \mathrm{ref}}}} \\
& \frac{\mathrm{k}_{\mathrm{L}} \mathrm{a}_{\mathrm{s}, \mathrm{lb}}}{\varepsilon_{\mathrm{lb}}}=0.5 \sqrt{\frac{\mathrm{D}_{\mathrm{L}, \mathrm{s}}}{\mathrm{D}_{\mathrm{L}, \mathrm{ref}}}}
\end{aligned}
$$

where $\mathrm{k}_{\mathrm{L}} \mathrm{a}_{\mathrm{s}}\left(\mathrm{s}^{-1}\right)$ is the overall mass transfer coefficient for species $\mathrm{s}, \varepsilon_{\mathrm{lb}}$ and $\varepsilon_{\mathrm{sb}}$ are the gas holdup for large bubbles and small bubbles (calculated by NPHASE), $\mathrm{D}_{\mathrm{L}, \mathrm{s}}\left(\mathrm{m}^{2} / \mathrm{s}\right)$ is the diffusivity for species $\mathrm{s}$ in the liquid phase, and $\mathrm{D}_{\mathrm{L}, \text { ref }}\left(\mathrm{m}^{2} / \mathrm{s}\right)$ is the reference diffusion coefficient [1] in the liquid $\left(2 \times 10^{-9} \mathrm{~m}^{2} / \mathrm{s}\right)$.

\section{Step 4: Calculate rates of absorption of reactant gas to bulk liquid phase}

Next, the rate of absorption is calculated for $\mathrm{CO}$ and $\mathrm{H}_{2}$ from the large bubbles and small bubbles, using the mass transfer coefficient calculated above and the equilibrium gas concentration in the liquid phase, based on the Henry's law constant. The Henry's law constant, $\mathrm{H}_{\mathrm{s}}$, is calculated from the calculated regression coefficients.

The following equation describes the rate of mass transfer $\left(\Gamma_{\mathrm{s}, \mathrm{k}}^{\prime \prime \prime}, \mathrm{mol} / \mathrm{m}^{3}-\mathrm{s}\right)$ for the solute (gas) into the solvent (liquid):

$$
\Gamma_{\mathrm{s}, \mathrm{k}}^{\prime \prime \prime}=\mathrm{k}_{\mathrm{L}} \mathrm{a}_{\mathrm{s}, \mathrm{k}}\left(\mathrm{c}_{\mathrm{s}}^{*}-\mathrm{c}_{\mathrm{s}, \mathrm{L}}\right)
$$

where

$$
\mathrm{C}_{\mathrm{s}}^{*}=\frac{\mathrm{C}_{\mathrm{s}, \mathrm{v}}}{\mathrm{H}_{\mathrm{s}}}
$$

where $\mathrm{c}_{\mathrm{s}}{ }^{*}$ is the equilibrium concentration of species $\mathrm{s}$ in the gas phase with the liquid $\left(\mathrm{mol} / \mathrm{m}^{3}\right), \mathrm{c}_{\mathrm{s}, \mathrm{L}}$ is the current concentration of species $\mathrm{s}$ in the liquid phase $\left(\mathrm{mol} / \mathrm{m}^{3}\right), \mathrm{c}_{\mathrm{s}, \mathrm{v}}$ is the current concentration of species $\mathrm{s}$ in the gas phase $\left(\mathrm{mol} / \mathrm{m}^{3}\right)$, and $\mathrm{H}_{\mathrm{s}}$ is the Henry's law constant for species $\mathrm{s}$, calculated above. Figure 3 depicts the concentration profiles at the gas bubble-bulk liquid interface. The diffusion coefficient controls the rate of mass transfer of gases into the bulk liquid, whereas the solubility determines the amount of gas that will dissolve eventually in the liquid phase.

Rates of absorption are calculated for $\mathrm{CO}$ and $\mathrm{H}_{2}$ from large and small bubbles, using the above method. Using these calculated rates of absorption, the resulting concentration of $\mathrm{CO}$ and $\mathrm{H}_{2}$ in the bulk liquid is calculated in NPHASE-CMFD. This concentration of $\mathrm{CO}$ and $\mathrm{H}_{2}$ will then be used in the 
reaction rate expressions given below. By combining the four equations listed above, the source terms for the conservation equations are obtained. The rates of absorption for the small bubbles is expressed as

$$
\begin{gathered}
\Gamma_{\mathrm{CO}, \mathrm{sb}}^{\prime \prime \prime}=1.0 \sqrt{\frac{\mathrm{D}_{\mathrm{L}, \mathrm{CO}}}{\mathrm{D}_{\mathrm{L}, \mathrm{ref}}}}\left(\left(\frac{\mathrm{c}_{\mathrm{CO}, \mathrm{v}}}{\mathrm{H}_{\mathrm{CO}}}\right)-\mathrm{c}_{\mathrm{CO}, \mathrm{L}}\right) \varepsilon_{\mathrm{sb}} \\
\Gamma_{\mathrm{H} 2, \mathrm{sb}}^{\prime \prime \prime}=1.0 \sqrt{\frac{\mathrm{D}_{\mathrm{L}, \mathrm{CO}}}{\mathrm{D}_{\mathrm{L}, \mathrm{ref}}}}\left(\left(\frac{\mathrm{c}_{\mathrm{H} 2, \mathrm{v}}}{\mathrm{H}_{\mathrm{H} 2}}\right)-\mathrm{C}_{\mathrm{H} 2, \mathrm{~L}}\right) \varepsilon_{\mathrm{sb}}
\end{gathered}
$$

and the rates of absorption for the large bubbles is expressed as

$$
\begin{gathered}
\Gamma_{\mathrm{CO}, \mathrm{lb}}^{\prime \prime \prime}=0.5 \sqrt{\frac{\mathrm{D}_{\mathrm{L}, \mathrm{CO}}}{\mathrm{D}_{\mathrm{L}, \mathrm{ref}}}}\left(\left(\frac{\mathrm{c}_{\mathrm{CO}, \mathrm{v}}}{\mathrm{H}_{\mathrm{CO}}}\right)-\mathrm{c}_{\mathrm{CO}, \mathrm{L}}\right) \varepsilon_{\mathrm{lb}} \\
\Gamma_{\mathrm{H} 2, \mathrm{lb}}^{\prime \prime \prime}=0.5 \sqrt{\frac{\mathrm{D}_{\mathrm{L}, \mathrm{H} 2}}{\mathrm{D}_{\mathrm{L}, \mathrm{ref}}}}\left(\left(\frac{\mathrm{c}_{\mathrm{H} 2, \mathrm{v}}}{\mathrm{H}_{\mathrm{H} 2}}\right)-\mathrm{C}_{\mathrm{H} 2, \mathrm{~L}}\right) \varepsilon_{\mathrm{lb}}
\end{gathered}
$$

In the CMFD code, $\Gamma^{\prime \prime}$ are the source terms for the ensemble-averaged phasic mass transfer rate.

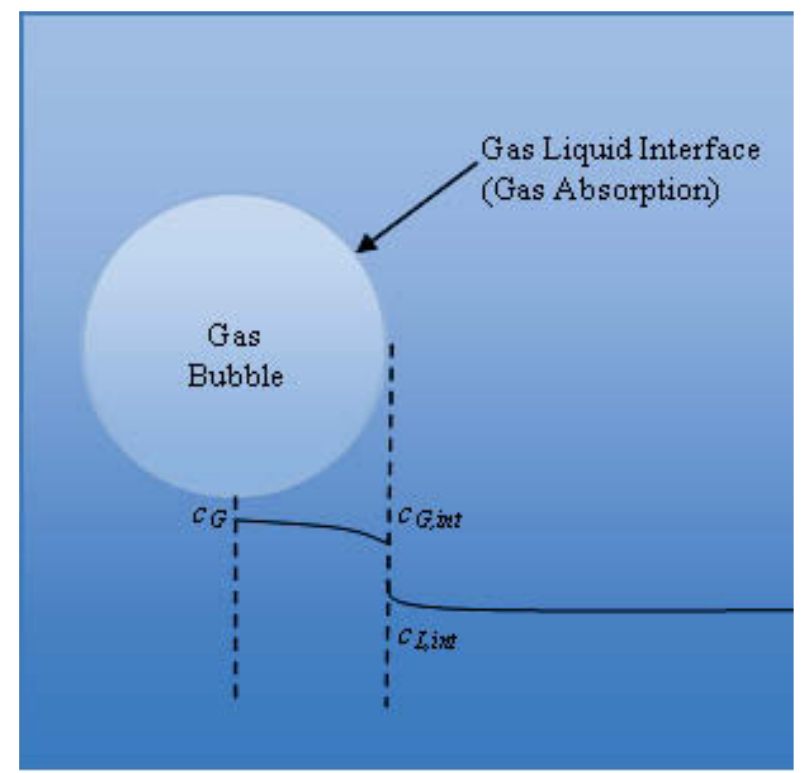

Figure 3. Concentration profile in the SBCR.

\section{Step 5: Calculate reaction rates}

To determine the consumption of $\mathrm{CO}$ and $\mathrm{H}_{2}$ for the FT reaction, it is necessary to calculate the molecules of carbon and hydrogen required to form the product to ensure that enough $\mathrm{CO}$ and $\mathrm{H}_{2}$ have absorbed into the wax phase and reacted on the catalyst surface for the reaction to proceed. This is a limitation of modeling the kinetics macrokinetically. Unfortunately, a microkinetic model of sufficient rigor does not currently exist for FT catalysts, so we are limited to a macrokinetic approach [31]. It is assumed that the catalyst particles are sufficiently small such that external and internal mass and heat transfer are not rate limiting. The intrinsic kinetic expression for the consumption of $\mathrm{CO}$ and $\mathrm{H}_{2}$, which is 
a Langmuir-Hinshelwood type expression, was based on data collected over a range of industrially relevant conditions. A macrokinetic approach using power rate laws is used, where the heterogeneous catalytic reaction is described by the following rate equations [2]

$$
\begin{gathered}
\mathrm{R}_{\mathrm{CO}}=\frac{-\mathrm{ac}_{\mathrm{CO}, \mathrm{L}} \mathrm{C}_{\mathrm{H}_{2}, \mathrm{~L}}}{\left(1+\mathrm{bc}_{\mathrm{CO}, \mathrm{L}}\right)^{2}} \\
\mathrm{R}_{\mathrm{H}_{2}}=2\left(\mathrm{R}_{\mathrm{CO}}\right) \\
\mathrm{R}_{\mathrm{H}_{2} \mathrm{O}}=-\left(\mathrm{R}_{\mathrm{CO}}\right) \\
\mathrm{R}_{\mathrm{HC}}=-\left(\mathrm{R}_{\mathrm{CO}}\right)
\end{gathered}
$$

with the kinetic constant, $\mathrm{a}\left(\frac{\mathrm{m}^{6}}{\mathrm{~kg}_{\mathrm{cat}} \mathrm{s} \mathrm{mol}}\right)$, and the adsorption coefficient, $\mathrm{b}\left(\frac{\mathrm{m}^{3}}{\mathrm{~mol}}\right)$, defined as follows

$$
\begin{aligned}
& a=8.852 \times 10^{-13} \exp \left[4494.41 \frac{1}{K}\left(\frac{1}{493.15}-\frac{1}{T}\right)\right]\left(R_{\text {gas }} T\right)^{2} \\
& b=2.226 \times 10^{-5} \exp \left[-8236.15 \frac{1}{K}\left(\frac{1}{493.15}-\frac{1}{T}\right)\right] R_{\text {gas }} T
\end{aligned}
$$

where $\mathrm{R}_{\mathrm{CO}}, \mathrm{R}_{\mathrm{H} 2}, \mathrm{R}_{\mathrm{H} 2 \mathrm{O}}$, and $\mathrm{R}_{\mathrm{HC}}\left(\mathrm{mol} / \mathrm{kg}_{\mathrm{cat}} \mathrm{s}\right)$ are the rates of consumption for $\mathrm{CO}$ and $\mathrm{H}_{2}$ and the rate of production for $\mathrm{H}_{2} \mathrm{O}$ and $\mathrm{HC}$, respectively, $\mathrm{R}_{\text {gas }}(\mathrm{J} / \mathrm{mol}-\mathrm{K})$ is the gas constant, and $\mathrm{T}(\mathrm{K})$ is the temperature of the catalyst. To obtain reaction rate in units of rate of change of moles per volume $\left(\frac{\mathrm{mol}}{\mathrm{m}^{3} \mathrm{~s}}\right)$, the reaction rates are multiplied by the density of the catalyst and the corresponding catalyst volume fraction.

To determine the number of moles of hydrogen and carbon in the product, it is assumed that the hydrocarbon product is a $\mathrm{C}_{\mathrm{n}} \mathrm{H}_{2 \mathrm{n}+2}$ (paraffin) molecule. Based on this calculation, the appropriate rate of hydrogen consumption, hydrocarbon production, and water production can be implemented. For instance, if the current temperature and pressure is $493.15 \mathrm{~K}$ and $2930271.85 \mathrm{~Pa}$, the volume fraction in the hydrocarbon product is approximately 0.9700 . The molecular weight of the liquid is $\sim 280.15 \mathrm{~g} / \mathrm{mol}$ and the molecular weight of the vapor is $24.47 \mathrm{~g} / \mathrm{mol}$. As a result the average molecular weight is

$$
\mathrm{MW}_{\text {avg }}=0.97 \cdot 24.47 \frac{\mathrm{g}}{\mathrm{mol}}+(1-0.97) \cdot 280.15 \frac{\mathrm{g}}{\mathrm{mol}}=32.14 \frac{\mathrm{g}}{\mathrm{mol}}
$$

based on the chemical formula $\mathrm{C}_{\mathrm{n}} \mathrm{H}_{(2 \mathrm{n}+2)}$, if the molecular weight of carbon is $12.011 \mathrm{~g} / \mathrm{mol}$ and the molecular weight of hydrogen is $1.00794 \mathrm{~g} / \mathrm{mol}, \mathrm{n}$ is equal to 2.15

$$
32.14 \frac{\mathrm{g}}{\mathrm{mol}}=12.011 \cdot \mathrm{n}+1.00794 \cdot(2 \mathrm{n}+2) \rightarrow \mathrm{n}=2.15
$$

and if the chemical reaction formula for the production of alkanes is as follows [32]

$$
\mathrm{nCO}+(2 \mathrm{n}+1) \mathrm{H}_{2} \rightarrow \mathrm{C}_{\mathrm{n}} \mathrm{H}_{(2 \mathrm{n}+2)}+\mathrm{nH}_{2} \mathrm{O}
$$

the rates of consumption and formation of $\mathrm{H}_{2}, \mathrm{H}_{2} \mathrm{O}$, and hydrocarbon product replace the generic rates previously given to 


$$
\begin{gathered}
\mathrm{R}_{\mathrm{H}_{2}}=\left(\frac{2 \mathrm{n}+1}{\mathrm{n}}\right)\left(\mathrm{R}_{\mathrm{CO}}\right) \\
\mathrm{R}_{\mathrm{H}_{2} \mathrm{O}}=-\left(\mathrm{R}_{\mathrm{CO}}\right) \\
\mathrm{R}_{\mathrm{HC}}=-\frac{1}{\mathrm{n}}\left(\mathrm{R}_{\mathrm{CO}}\right)
\end{gathered}
$$

The reaction rates are multiplied by the density of the catalyst and the corresponding catalyst volume fraction and inserted into Equation 7.

\section{Step 6: Partition products among fields}

After the rates of formation are determined, the products formed must be partitioned to either the liquid or vapor phase. Therefore, the moles of hydrocarbon product formed are partitioned to the liquid wax phase by multiplying the moles formed by one minus the vapor fraction. The moles of vapor product (i.e., $\mathrm{C}_{1}$ to $\mathrm{C}_{4}$ hydrocarbons) are the vapor fraction times the moles formed. The vapor product is assumed to be equally divided amongst the various bubble sizes. It should be noted that the coefficients of the reaction expressions, i.e. how many moles of $\mathrm{CO}$ and $\mathrm{H}_{2}$ are reacted are dependent upon the number of $\mathrm{CO}$ and $\mathrm{H}_{2}$ molecules formed in the reaction product. To determine this, the volume fraction of the hydrocarbon product is calculated, based on the current temperature and pressure. The molecular weight of the hydrocarbon mixture is then calculated using Equation 69 from the corresponding volume fraction of liquid and vapor using the equations for the vapor and liquid molecular weights. The coefficients in the regressed equations for volume fraction, $\varepsilon$, and molecular weights, MW, of the hydrocarbon product are used to calculate the molecular weight of the mixture.

$$
\mathrm{MW}_{\mathrm{HC}, \text { mix }}=\varepsilon_{\mathrm{HC}} \mathrm{MW}_{\mathrm{HC}, \mathrm{v}}+\left(1-\varepsilon_{\mathrm{HC}}\right) \mathrm{MW}_{\mathrm{HC}, \mathrm{L}}
$$

The water product formed is then determined to be either a liquid or vapor product. This is accomplished by inputting the current temperature into the regression equation for water partial pressure. If the calculated pressure is less than the current system pressure, the water formed is a liquid product and joins the wax phase, if the pressure is greater than or equal to the current pressure the water is in the vapor phase and should be partitioned equally amongst the various bubble sizes.

\section{Step 7: Calculation of gas mixture properties}

The resulting properties of the gas phase for all bubble sizes and the liquid phase are calculated using general mixture rules for the next computational node following steps one and two above. The mixture rule given by Equation 46 is used to obtain the properties of the gaseous and liquid mixtures. However, the gas mixture now must include the gaseous properties of the hydrocarbon product formed, and depending on which phase it is present in, either the liquid or gas phases must include the water mixture properties.

\section{Step 8: Repeat Steps 3 through 7 above}

Steps three through seven described above are repeated with updated temperatures and pressures from the CMFD solution. This procedure continues until convergence of the CMFD simulation has been achieved. 


\section{Summary and Future Work}

A CMFD model developed for simulation of FT reactions in a SBCR has been presented. Results of the hydrodynamic simulations have been compared to experimental data for adiabatic, churn-turbulent flows to assess the fidelity of the two-phase flow simulation capability. A four-field, 13-species model was created to predict churn-turbulent flows in a SBCR. The churn-turbulent flow is modeled as a continuous liquid phase with two dispersed bubble size groups. Each bubble group is treated as a separate field to allow appropriate flow physics for the different bubble size groups to be included via the closure models. The use of mechanistic closure models to account for interfacial momentum transfer between the bubbles and the liquid wax was presented. Bubble breakup/coalescence and two-phase turbulence submodels incorporated into the NPHASE-CMFD code were described. A property method approach to incorporating VLE into the calculation is outlined. An Aspen Plus simulation was executed and the resulting data was regressed into a set of equations for the physical and thermodynamic properties that are functions of reactor temperature and pressure. This approach allows the incorporation of VLE without all the complexity of performing time-consuming calculations within the CMFD code.

Future work to improve on the VLE submodel includes obtaining an expression for alpha (i.e., the product distribution) as a function of temperature and pressure. A more detailed model of the heat exchanger tubes within the SBCR, including the pressure drop due to the presence of internals, should be included.

This paper provides a testing and validation hierarchy for the complete CMFD model. Results of CMFD simulations for the hydrodynamics compare favorably with experimental data. A more comprehensive validation of the simulation with the integrated effects of hydrodynamics and chemistry is necessary.

\section{Acknowledgments}

Funding for this research was supported by the U.S. Department of Energy, Office of Nuclear Energy, under DOE Idaho Operations Office Contract DE-AC07-05ID14517.

\section{References}

1. Maretto, C. and R. Krishna, Modelling of a bubble column slurry reactor for Fischer-Tropsch synthesis. Catalysis Today, 1999. 52(2-3): p. 279-289.

2. Yates, I.C. and C.N. Satterfield, Intrinsic Kinetics of the Fischer-Tropsch Synthesis on a Cobalt Catalyst. Energy \& Fuels, 1991. 5: p. 168-173.

3. Drew, D.A., Passman, S.L.. Theory of Multicomponent Fluids. Applied Mathematical Sciences, 1998. Vol. 135.

4. $\quad$ Ranade, V.V., Computational Flow Modeling for Chemical Reactor Engineering. Vol. 5. 2002: Academic Press.

5. Podowski, M.Z., On the Consistency of Mechanistic Multidimensional Modeling of Gas/Liquid Two-Phase Flows. Nucl. Eng. Des., 2009. 239: p. 933-940.

6. Krishna, R., J. Ellenberger, and S.T. Sie, Reactor development for conversion of natural gas to liquid fuels: A scale-up strategy relying on hydrodynamic analogies. Chemical Engineering Science, 1996. 51(10): p. 2041-2050.

7. Lopez de Bertodano, M., Sun, X., Ishii, M., Ulke, A., Phase Distribution in the Cap Bubble Regime in a Duct. Journal of Fluids Engineering, 2006. Vol. 128: p. p. 811-818. 
8. Lucas, D., Beyer, M., Kussin, J., Schutz, Benchmark Database on the Evolution of Two-Phase Flows in a Vertical Pipe, in XCFD4NRS, OECD/NEA \& International Atomic Energy Agency (IAEA) Workshop. 2008: Grenoble, France.

9. Ishii, M., Zuber, N., Drag Coefficient and Relative Velocity in Bubbly, Droplet or Particulate Flows. AIChE Journal, 1979. Vol. 25: p. p. 843-855.

10. Antal, S.P., M.Z. Podowski, R.T. Lahey, Jr., D. Barber, C. Delfino, Multidimensional Modeling of Developing Two-Phase Flows in a Large Adiabatic Riser Channel, in The 11th International Topical Meeting on Nuclear Reactor Thermal-Hydraulic (NURETH-11). 2005: Popes Palace Conference Center, Avignon, France.

11. Yelash, L.V., T. Kraska, and U.K. Deiters, Closed-Loop Critical Curves in Simple Hard-Sphere van der Waals-Fluid Models Consistent with the Packing Fraction Limit. Journal of Chemical Physics, 1999. 110(6): p. 3079-3084.

12. Prince, M.J., Blanch, H.W., Bubble Coalescence and Breakup in Air-Sparged Bubble Columns. AIChE Journal, 1990. Vol. 36(10): p. p. 1485-1499.

13. Sato, Y., Sekoguchi, K., Liquid Velocity Distribution in Two-Phase Bubble Flow. Int. J. Multiphase Flow, 1975. Vol 2: p. 79-95.

14. Sato, Y. and M. Sadatomi, Momentum and Heat Transfer in Two-Phase Bubble Flow - I. International Journal of Multiphase Flow, 1981. 7(2): p. 167-177.

15. Jakobsen, H., Chemical Reactor Modeling: Multiphase Reactive Flows. 2008: Springer-Verlag.

16. Lucas, D., Krepper, E., Prasser, H.-M., Prediction of Radial Gas Profiles in Vertical Pipe Flow on the Basis of Bubble Size Distribution. Int. J. Therm. Sci., 2001. Vol. 40: p. p. 217-225.

17. Lucas, D., Krepper, E., Prassar, H.-M., Use of Models for Lift, Wall and Turbulent Dispersion Forces Acting on Bubbles for Poly-Disperse Flows. Chemical Engineering Science, 2007. Vol. 62: p. p. 4146-4157.

18. Nedeltchev, S., Simultaneous Application of Penetration Theory to Both Small and Large Bubbles Formed in a Column Operated Under Heterogeneous Regime. Chem. Eng. Technol., 2008. Vol. 31(No. 2): p. p. 315-323.

19. Liu, Y., Hibiki, T., Sun, X., Ishii, M., Kelly, J.M., Drag Coefficient in One-Dimensional TwoGroup Two-Fluid Model. International Journal of Heat and Fluid Flow, 2008. Vol. 29: p. p. 14021410.

20. Wallis, G.B., One-Dimensional Two Phase Flow. 1969, New York: McGraw-Hill.

21. Clift, R., Grace, J.R., Weber, M.E., Bubbles, Drops, and Particles. 1978, Mineola, NY: Dover Publications, Inc.

22. Tomiyama, A., Tamai, H., Zun, I., Hosokawa, S., Transverse Migration of Single Bubbles in Simple Shear Flows. Chem. Eng. Sci., 2002. Vol. 57: p. p. 1849-1858.

23. Wellek, R.M., Agrawal, A.K., Skelland, A.H.P, Shapes of Liquid Drops Moving in Liquid Media. AIChE Journal, 1966. Vol. 12: p. p. 854-860.

24. Lucas, D., Krepper, E., Prasser, H.-M., Manera, A., Investigations on the Stability of the Flow Characteristics in a Bubble Column. Chem. Eng. Technol., 2006. 29(9): p. p. 1066-1072.

25. Kurul, N., Podowski, M.Z. (1990). Multi-dimensional Effects in Sub-cooled Boiling. in Proceeding of the 9th Heat Transfer Conference. 1990. Jerusalem, Israel.

26. Guillen, D.P., et al., Optimization of a Two-Fluid Hydrodynamic Model of Churn Turbulent Flows, in Proceedings of the 17th International Conference on Nuclear Engineering, ICONE1775113. 2009: Brussels, Belgium.

27. Antal, S.P., R.T. Lahey, Jr., Flaherty, J.E., Analysis of Phase Distribution in Fully-Developed Laminar Bubbly Two-Phase Flow. International Journal of Multiphase Flow, 1991. Vol. 17(Issue 5): p. p. 635-652.

28. Ong, B., Experimental Investigation of Bubble Column Hydrodynamics - Effect of Elevated Pressure and Superficial Gas Velocity, in Department of Chemical Engineering. 2003, Washington University: Saint Louis, Missouri. 
29. Mudde, R.F., Gravity-Driven Bubbly Flows. Annual Rev. Fluid Mech., 2005. Vol. 37: p. p. 393423.

30. Gribik, A., D.P. Guillen, and D. Ginosar, Kinetic Modeling of a Fischer-Tropsch Reaction over a Cobalt Catalyst in a Slurry Bubble Column Reactor for Incorporation into a Computational Multiphase Fluid Dynamics Model, in International Pittsburgh Coal Conference 2008. 2008, September 29 - October 2, 2008: Pittsburgh, PA.

31. Bartholomew, C.H., Farrauto, R.J., Fundamentals of Industrial Catalytic Processes. Second Edition ed. 2006, Hoboken, NJ: John Wiley \& Sons, Inc. p. 402-404.

32. Steynberg, A.P., and Dry, M.E., Fischer-Tropsch Technology. Studies in Surface Science and Catalysis, ed. G. Centi. Vol. 152. 2006: Elsevier. 